\title{
A Reference Model of Reverse Logistics Process for Improving Sustainability in the Supply Chain
}

\author{
Faustino Alarcón ${ }^{1}\left(\mathbb{D}\right.$, Pascual Cortés-Pellicer ${ }^{2, *} \mathbb{E}$, David Pérez-Perales ${ }^{1}$ and Ana Mengual-Recuerda ${ }^{2}$ (D) \\ 1 Research Centre on Production Management and Engineering (CIGIP), Universitat Politècnica de València, \\ 46022 València, Spain; faualva@omp.upv.es (F.A.); dapepe@omp.upv.es (D.P.-P.) \\ 2 Department of Business Management, Universitat Politècnica de València, 46022 València, Spain; \\ anmenre1@upv.es \\ * Correspondence: pascorpe@omp.upv.es
}

Citation: Alarcón, F.; Cortés-Pellicer,

P.; Pérez-Perales, D.; Mengual-

Recuerda, A. A Reference Model of

Reverse Logistics Process for Improving Sustainability in the Supply Chain. Sustainability 2021, 13, 10383. https://doi.org/10.3390/ su131810383

Academic Editor: Sebastian Kot

Received: 1 August 2021

Accepted: 11 September 2021

Published: 17 September 2021

Publisher's Note: MDPI stays neutra with regard to jurisdictional claims in published maps and institutional affiliations.

Copyright: (c) 2021 by the authors. Licensee MDPI, Basel, Switzerland. This article is an open access article distributed under the terms and conditions of the Creative Commons Attribution (CC BY) license (https:// creativecommons.org/licenses/by/ $4.0 /)$.

\begin{abstract}
The reverse logistics process (RLP) has become a key process for the supply chain (SC) given its importance for treating the increasing quantity of returned or recovered products and its impact on sustainability. However, the RLP is complex and involves a high degree of uncertainty and difficult decisions that affect SC efficiency. One of the aspects that can help the most to reduce this complexity and to improve SC efficiency is to formalize this process. The consulted studies agree on the numerous benefits of RLP formalization, but no tools, methodologies or specific solutions were found that help companies to advance in this matter. This work aims to develop a specific tool for RLP formalization so that its efficiency can be increased, leading to an improvement of SC sustainability. The main results comprise a reference model for RLP (RM-RLP) and an associated methodology so that any company can formalize its RLP by modeling its activities. The proposed tool (RM-RLP and methodology) is applied to a closed loop SC of relaxing chairs as an example of RLP formalization, proving its usefulness and, additionally, the improvements that can be reached in three RLP key indicators: total process duration, customer response time and the perceived autonomy and trust of the workers participating in the process.
\end{abstract}

Keywords: reverse logistics process; sustainability; supply chain; formalization; reference model

\section{Introduction}

Many products at the end of their useful life either generate or become toxic harmful waste for human health and the environment. Not properly handling this waste can seriously damage the environment and the ecosystem in general [1]. These waste-handling problems, together with the overexploitation of natural resources and the limited capacity to sustainably absorb all the generated products, are raising society's awareness about respecting environmental conservation [2].

This situation leads public administrations to approve new laws that favor the reuse of raw materials, minimize environmental impacts and extend products' useful lives [3]. This means that companies have to manage recovery reverse flows and product treatment [4] and define sustainability-based policies [5] to comply with legislation and reduce environmental impacts, as well as maximize the economic value of its products and production processes to improve their society image [6-8]. In short, supply chains (SCs) feel compelled to adopt reverse logistics (RL) activities for competitive, marketing, economical and environmental reasons [9].

RL can be defined as "a process whereby firms can become more environmentally efficient through recycling, reusing and reducing the amount of materials used" [10]. One year later, the Council of Logistics Management proposed a definition that more explicitly refers to the reverse flow of products: "the process of planning, implementing, and controlling the efficient, cost effective flow of raw materials, in-process 
inventory, finished goods, and related information from the point of consumption to the point of origin for the purpose of recapturing or creating value or proper disposal" [11].

Incorporating a reverse logistics process (RLP) and building appropriate SC partnerships have become relevant issues given their importance in operations, customer service and, more particularly, in sustainability [12-15]. In fact, the ability to manage returns has become a critical success factor for many firms [16].

However, although there are multiple benefits and drivers for a company to implement RL [17], only a few companies have appropriate strategies for managing product return, while most tend to ignore it, anchored to the conventional approach of traditional or forwards SCs [18]. This is due to the introduction of RL into organizations being not trivial for several reasons.

First, because it involves a strategical decision that requires evaluating a large set of criteria that includes strategical, operational, tangible and intangible dimensions [13]. Second, because there are several important barriers that make RLP implementation extremely difficult [19]. Finally, because the companies have been operating with direct distribution systems for many years and they forget that the RL is based on a new concept and that its design, based exclusively on direct logistics, can make it inefficient and expensive [20].

In this sense, traditional inventory management models and ordering policies, for example, are unsuitable in RL [21], mainly because order and inventory variance amplification impact SC dynamics [22]. So the success of RLP implementation requires a new point of view, as well as the coordination of forward and backward flows of materials and information [23].

Another important aspect that makes RLP implementation and management difficult is the lack of formalization. A lack of formal policies may inhibit the effectiveness of RL [16] and can be detrimental for this process, especially when senior management states the general objective of the process but no clear consensus has been reached about what operations are needed and how they must be carried out by the involved personnel [24].

Formalization refers to the level at which rules, procedures, instructions and communications are established and written so that all stakeholders understand what is expected [25] which is, therefore, a key aspect to guide and control intrafirm or interfirm (i.e., SC) operations [26]. Thus, drawing up a formal plan can help employees to manage RL programs/processes in a more effective and controlled manner [27]. For this reason, the RLP formalization level may be a clear indication of the degree of a company's control over its RL operations [28].

Having a formalized RLP allows firms to properly manage customer expectations as regards returns [16,28] and may also benefit organizations [24,28]. Moreover, formalization, along with up-skilling the people involved in recovery activities, are important enablers for developing the RL system [29].

It is widely believed that formalization enhances performance by eliminating ambiguity and clarifying priorities while developing rules and procedures [29-31]. This RL formalization also reduces complexity [32] and can improve a firms' efficiency because standardizing repetitive activities does away with the need to treat every event as a new decision [33]. In an RLP, formalization can mean, for example, decision rules to determine whether products should be scrapped, discarded, repaired, overhauled or sold on a secondary market [34,35].

For all these reasons, and given the continuing rise in product returns in today's e-commerce environment, many companies attempt to formalize their RLP [36]. Undoubtedly, lack of standardized processes has become a key RL challenge in the early formalization and RL field [37]. Accordingly, Huscroft et al. [24] suggest, for future research, ways to increase RLP formalization to convert these processes into profit centers within organizations, which is perhaps one of the areas that most requires further scholarly research.

Despite the evident relevance of RLP formalization for SC efficiency and effectiveness, it is not an easy task to identify, structure, define or standardize its operations and, therefore, 
to act in a clear consensual manner against cases of returned or recovered products. This is not only due to the high uncertainty in the quantity, quality and timing of reverse flows, but also to the marked casuistry and wide variety of possible states in recovered products, along with those responsible for this matter lacking confidence and training in this matter. The consulted studies clearly identify this problem and document and extensively describe it, but do not offer any tools or specific solutions for company practitioners to move toward RLP formalization.

In order to bridge this gap, the present work proposes a reference RLP model (RMRLP) that includes all the RLP casuistry so that companies can use it as a pattern or an example to formalize their own RLP and to improve SC sustainability. To supplement this reference model, a 3-step methodology was developed to guide companies to swiftly and simply formalize and design their own models. The proposed methodology is based on the method of selecting or eliminating the generic activities contained in the reference model in accordance with each company's case to represent and formalize the RLP of each specific case. After presenting the RM-RLP and the methodology, an application example is included to demonstrate the usefulness of the proposal which can serve as a guide for future applications.

The methodology followed to develop these three results (RM-RLP, methodology and application example) consists of the following steps: (1) identification of the macro-activities of the RLP from the analysis of the literature review; (2) validation of the macro-activities and its detailed description in procedural format, based on our experience and knowledge of the RLP of several companies with which we have been working in recent years and the information obtained in the literature review; (3) development of the reference model based on the BPMN 2.0 language; (4) proposal of a methodology to guide users in the process of adapting the RM-RLP to each company's particular case; (5) application of the RM-RLP and the methodology to a closed loop SC; and (6) validation of the RM-RLP and methodology through the formulation of three hypotheses based on three performance indicators related with the efficiency of the RLP.

The remainder of this paper is organized as follows. Section 2 presents the conducted literature review to describe the relationship among RL, SC and sustainability concepts, to identify the activities comprising RLP and to justify the importance of RLP formalization. Section 3 describes the proposed RM-RLP and an easy methodology for its use. Section 4 offers a case study in which the proposed RM-RLP is applied, while in Section 5 a quantitative assessment of the usefulness of that tool is conducted by validating some hypotheses related to the expected improvements derived from the RLP formalization. Finally, Section 6 draws some conclusions and future research lines.

\section{Theoretical Background}

Several studies have evidenced and quantified gains and savings due to sustainability initiatives in SCs [38]. So in the past two decades, sustainable SC management (SSCM), which integrates environmental, social and economic goals across a focal firm's SC processes, has emerged as an approach for firms to improve sustainable (i.e., environmental, economic and social) outcomes in their SCs [39]. Firms are increasingly considered accountable for the sustainable outcomes of their internal operations and their suppliers operations [39]. Thus, to a certain extent, SSCM is considered the advent of a new era that incorporates environmental performance, social performance and economic contribution, which has been referred to as an intersection of three sustainable development spheres [38]. In fact, sustainable development is presently considered a critical goal for organizations given its impact on achieving long-term competitiveness, and sustainability has made firms rethink their strategies and situation in the market [12].

Carter and Rogers [40] defined SSCM as "the strategic, transparent integration and achievement of an organization's social, environmental, and economic goals in the systemic coordination of key inter-organizational business processes for improving the long-term economic performance 
of the individual company and its supply chains". Other definitions of this concept can be consulted in the works of Ahi and Ansari [38,41].

According to Ansari and Kant [38], integrating sustainability concepts into SCs' core business functions enables organizations' competitiveness to improve. Hence, transformation from SCM to SSCM places considerable pressure on organizations that work to modify their existing SCs to fulfill sustainability requirements. However, establishing SSCM to manage sustainability in SCs is still a difficult target to reach [39].

Researchers link sustainability concepts with SCM through different perspectives using various terms [38,41], for example: SSCM and green supply chain management (GSCM) [42], environmental sustainability [43], sustainable SC quality management (SSCQM) [44] and RL/closed loop SC and social sustainability [45].

On the other hand, sustainability theory directs organizations to incorporate various types of practices [38]. Some are more environmental- or economic-oriented, such as returning products to producers at their end of life (reverse logistics), the eco-friendly handling of returns and the diffusion of environmentally friendly strategies at each SC level, and others are more social-oriented ones, such as providing better working conditions, fair compensation, equal human rights and cultural diversity.

Of all these practices, that which undoubtedly and most strongly impacts SC sustainability is RLP incorporation [12].

RL has become a key competence of modern SCs [46], mainly for its importance for recovering the value of products and managing their disposal [11]. Geng et al. [47] demonstrate that RL shows an overall moderate impact on three performances: economic, environmental and operational. RLP also helps companies to comply with governmental regulations, reduce the use of raw materials and waste generation and improve their image with customers and society in general $[7,8,45]$. Thus, SCs feel compelled to adopt RL activities for economic, environmental, marketing and competitive reasons [9].

Therefore, some authors such as Narayana et al. [48] highlight that RL management is a key element for fulfilling the sustainable development goals of any organization. According to Winter and Knemeyer [49], a review of the existing sustainable SC literature determines that RL forms part of sustainability due to recycling aspects and green SC issues. Moreover, Morgan et al. [50] even merge the terms of sustainability and RL into the concept of sustainable reverse logistics. Adapting this concept to recent sustainability literature, they define the concept of sustainable reverse logistics capability as "the organization's ability to develop ways of responding to changing partner, customer, and environmental sustainability requirements by way of $R L P$ management". In their research, empirical evidence is provided to address the importance of sustainable reverse logistics as a key component of a successful SC strategy.

This clearly shows the relationship between RL and sustainability concepts [51], and is one of the reasons why more attention has been paid to the strategic application of RL to improve the claim of products at the end of their useful lives [17,45].

This work proposes a reference model to guide companies to formalize their RLP as a means to improve SC sustainability. Initially, the literature search was focused on process-based reference models for the RLP formalization, using for that the keywords: reverse logistic and reference model. No relevant studies were found so this search was redirected and expanded to other ones, allowing to obtain information about the RLP composition and its formalization. Therefore, the remainder of this literature review section contemplates two main issues: (1) works that help to know the RLP in detail, its activities and its operation and (2) works that address the relevant aspects of RLP formalization. The following keywords have been used for the search of relevant literature about these two main issues: (1) reverse logistics and (process, activities, disposition decision), and (2) reverse logistics and formalization. 


\subsection{RLP Activities}

The work of Rogers and Tibben-Lembke [19] analyzes several definitions of RL. Their analysis shows that, from the work of Carter and Ellram [10], the word "process" is included in the definitions of RL. A process is, in turn, defined as " ... a collection of activities that takes one or more kinds of input and creates an output that is of value to the customer ... " [52,53]. Incorporating this word into the RL definition therefore recognizes that RL is a set of activities. In this section, precisely those activities making up the RLP are identified by reviewing relevant publications in order to, and based on these activities, propose a generic model that can be used as a reference for designing RLPs in specific companies. As some of these activities are repeated or are similar, only the descriptions that are strictly necessary to provide a minimum understanding of the RLP operation are provided. Having identified RLP in this first part of the section, a framework for a comparative analysis of the consulted literature was conducted.

One of the relevant works about RL is that of Fleischmann et al. [54]. These authors divide the RLP into the following activities: (1) collection, which refers to the action of collecting the recovered products and physically moving them to some point where subsequent operations can be performed; (2) selection, consisting of determining each product's treatment-from this point onward, flow separation comes into play between reprocessing and disposal operations; (3) reprocessing, which implies transforming a used product into a newly usable product; (4) disposal, consisting in deciding which path the products that cannot be reused for technical or economic reasons must follow; and (5) redistribution, which refers to the action of marketing reusable products to a potential market and physically transferring them to potential future users to be reused.

According to De Brito and Dekker, [55], the overall RL activities are confined to (1) collection, followed by (2) inspection/selection/sorting activity, (3) reprocessing and, finally, (4) redistribution. Reprocessing can be more or less light and is discriminated into two groups. The first is direct recovery, where returned products are in an as-good-as-new condition and anyone can directly reuse, resell and proceed to redistribution. The second group, process recovery, involves more elaborate reprocessing.

Agrawal et al. [56] present their review of the literature about the RLP and identify the same four key stages as in Banihashemi et al. [12]: (1) product acquisition, which is the process of acquiring used products, components or materials from end users for further processing; (2) collection; (3) inspection/sorting; and (4) disposition, defined as treating the product for repair, remanufacturing, recycling, reuse or final disposal, depending on the disposition decision made to either recapture value or dispose of it.

Another interesting study that reviews the literature on key RLP activities is that by Sangwan [57]. This paper aims to describe the various sub-activities, decision variables and performance indicators that constitute the following three basic RL SC activities: (1) collection; (2) inspection and sorting; and (3) product recovery, an important activity to manage the flow of products or parts destined for remanufacturing, repairing or disposal, and to effectively use resources.

In the work by Sellitto [58], the RL activities in three companies are analyzed with the purpose to identify opportunities to recover value from waste in the process industry. These activities were the following: (1) waste identification, (2) collection, (3) sorting, (4) compaction, (5) intermediate storage, (6) recollection, (7) transportation, (8) delivery and (9) value recovery.

Presley et al. [13] propose a management methodological framework based on RL activities that is used as a vehicle to frame decisions using corporate sustainability. For these authors, RLP contains the following activities: (1) collection, (2) separation and inspection, (3) storage, (4) disassembly processing, (5) shredding and grinding, and (6) outbound logistics.

In slightly more detail than previous works, Genchev et al. [28] identify the following RLP activities: (1) initiate returns, where the customer seeks a return approval from the firm or sends the return directly to the returns center; (2) determine routing, that is, the 
mode of transportation and destination of returned products; (3) receive returns, which includes verifying, inspecting and processing the returned product by selecting disposition; (4) select disposition, which consists in assigning codes to the processed return and the accurate determination of disposition options; (5) credit customer/supplier, which involves charging payment back to the buyer's account, including credit authorization and potential claim settlements with customers; and (6) analyze returns and measure performance, which establish appropriate controls.

Concept of sustainability and logistics is discussed by Rad and Gulmez [59], focusing on environmental, economic and social dimensions of sustainable logistics. In this study, a detailed list of RLP activities is also mentioned: (1) planning, (2) collecting, (3) transport, (4) storage, (5) processing, (6) receiving, (7) recycling, (8) packaging, (9) shipping, (10) reducing, (11) management, (12) elimination and (13) controlling.

Han and Ponce-Cueto [60] propose a theoretical framework to help companies formalize their reverse logistic programs and divide the whole RLP into: (1) initiating returns, (2) transporting returns to collection points, (3) receiving returns at collection points, (4) the inspection/separation procedure and (5) the reprocessing procedure. The last two operations, which focus on treating facilities for returns, can be carried out by (6) treating returns in-house or by outsourcing. Finally, related activities also include: (7) feedback to the customer/supplier, which refers to sending feedback about a buyer's requirements, including credit authorization and claim settlements with customers; and (8) measuring RL formalization performance, which defines the metrics to measure product or process performance.

An important part of the RLP is formed by the treatment alternatives for recovered products. Alarcón et al. [51] reviewed the literature on this matter and conclude that the widely accepted alternative dispositions are: (1) direct reuse and resale, (2) repair, (3) refurbishing, (4) remanufacturing, (5) cannibalization, (6) recycling, (7) incineration and (8) landfilling.

Having identified the main activities (macro-activities) making up the RLP after reviewing previous works, a framework for their comparative analysis was proposed. For this purpose, one of the most widely accepted RL definitions in the scientific community was recalled, that of Rogers and Tibben-Lembke [19], which, as previously mentioned in the Introduction, draws on the proposal of the Council of Logistics Management and defines RL as "the process of planning, implementing, and controlling the efficient, cost effective flow of raw materials, in-process inventory, finished goods, and related information from the point of consumption to the point of origin for the purpose of recapturing or creating value or proper disposal" (p. 130).

An analysis of this definition allowed us to verify that the same three macro-activities to describe the RLP are mentioned: planning, implementing and controlling. Besides, these three macro-activities roughly coincide with the general phases of a business process' life cycle [61].

This RLP review also shows that no consensus has been reached about the activities that make it up. The consulted works differ in not only the number of activities making up the RLP, but also in the way they are named and even their level of detail (i.e., the decomposition level of the process). By contemplating this heterogeneity, an initial framework was defined to make a global comparison of all the works which comprised the three macro-activities mentioned in the previous definitions: planning, implementing and controlling.

A more in-depth RLP review confirmed that most of the activities mentioned for the RLP correspond to the implementation or execution phase in the process which, in turn, is also the most relevant phase for our work. This is because the proposed reference model aims to guide companies to define and formalize their own RLPs, where operation or execution activities are particularly relevant. For this reason, in a second iteration, we have expanded or disaggregated the implementing macro-activity into three activities, regrouping and reorganizing the most mentioned and determining activities in the literature. In 
this way, a somewhat more exhaustive framework has been obtained that can be used to present, in a global way, the main findings in the consulted literature.

These three activities are:

1. Collection and transport. They consist of collecting and taking the product from the customer to the company. Regardless of how the process starts, the customer starts/generates the process while the company ends up treating the product. Therefore, this first stage connects the customer with the company.

2. Inspection and sorting. In this activity, the company inspects and assesses the product collected from the customer. This stage is crucial for the RLP because, by means of the product disposition decision (DD) made, each product is inspected to determine what to do with it (reuse, intervene in the product to place it back on the market, use of components or controlled removal).

3. Product disposition. With this activity, the company delivers products to its environment depending on the different disposal alternatives.

Next, we present the proposed framework for the comparative analysis of the consulted works (Scheme 1). This scheme has as many rows as consulted works. There are also six columns, of which the first is used to reference each work while the others represent the main RLP activities. This allows the activities proposed for each work to be allocated to the right columns corresponding to the main RLP activities.

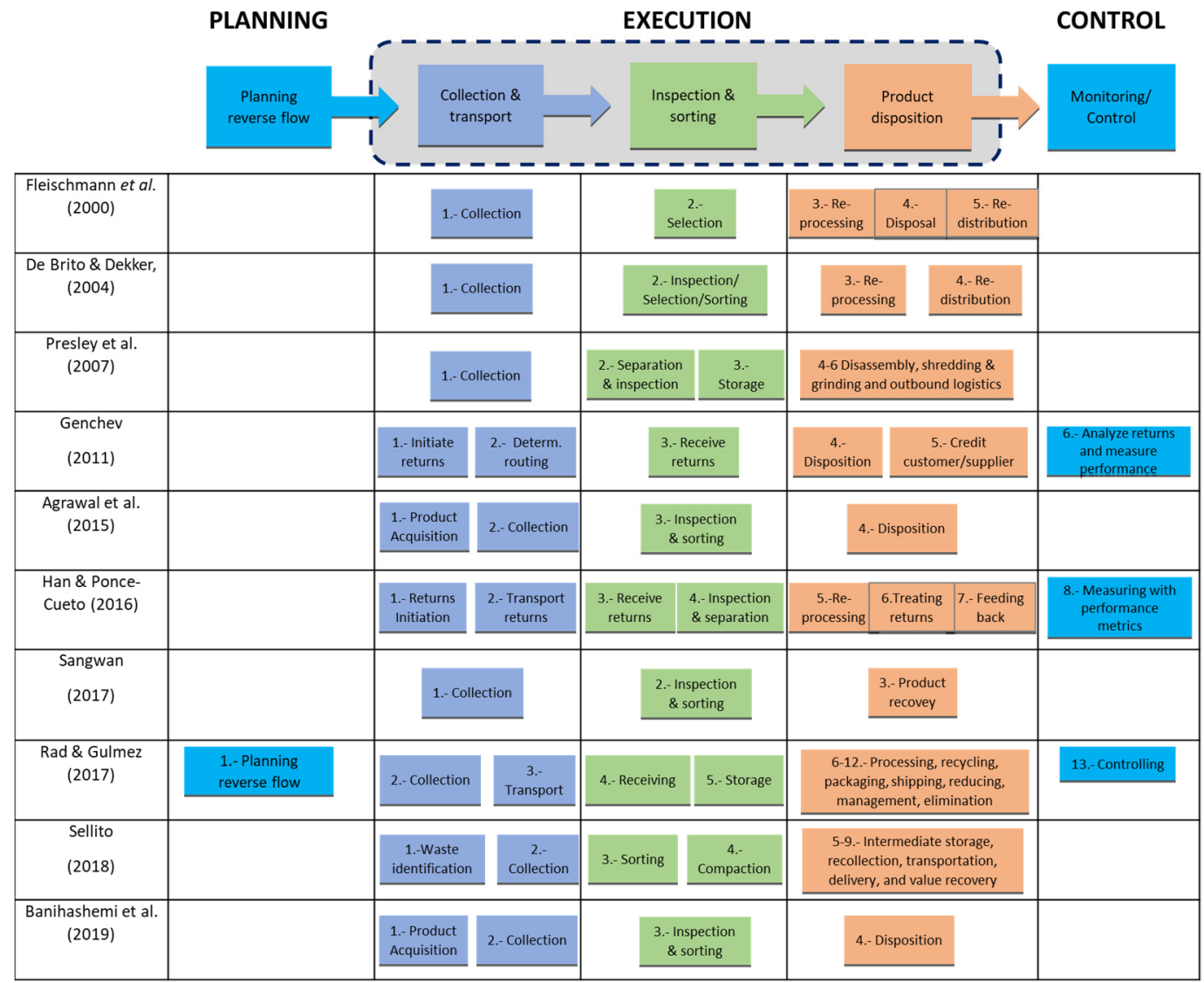

Scheme 1. Framework for the comparative analysis of the consulted works (ordered by year).

As previously mentioned, the framework clearly shows that most of the activities mentioned in the consulted works appear in activities collection/transport, inspection/sorting and disposition, which correspond to the RLP execution or implementation macro-activity.

However, the consulted works do not show a sufficiently detailed and complete vision to facilitate RLP formalization. To this end, a reference model is presented in the next 
section, in which the activities corresponding to the RLP implementation or execution macro-activity are defined in more detail.

\subsection{RLP Formalization}

Increasingly more researchers are attaching importance to formalization in RL, and research contributions on this topic have increased since 1985 [60]. One of the main reasons for this interest is its positive impact on the sustainable outcomes of SCs. The other reason is the importance of $\mathrm{RL}$ as a response to increasing commercial returns, especially in e-commerce [36]. This is becoming a real problem in the modern hypercompetitive marketplace, where firms vigorously compete based on customer service and are consequently more liberal than ever before in allowing returns $[62,63]$. Indeed, many firms will accept almost anything sent back up the channel, regardless of the reason or condition, if they perceive that doing so can benefit the customer relationship [63,64].

Formalization was initially defined as a concept that "denotes the extent to which rules, procedures, instructions, and communications are written" [25]. Genchev et al. [28] offer a more concise definition where formalization refers to the "written rules and procedures agreed on about a particular business operation".

Some other researchers highlight that formalization can be implemented with such tools as articulated and/or written policies, job description and roles, organizationalresponsibility charts, strategical and operational plans, objective-setting systems, standardization of processes and formalized communication systems, which are intra- and interfirm $[65,66]$.

According to Ruekert et al. [31], the greater the formalization of a given task, regardless of being organized internally or externally, the greater the efficiency of its performance, especially when the following conditions occur: task duration is short, the task is repetitive, performance outcomes can be easily and accurately assessed and the task environment is stable and not complex. It is worth noting that, if an organization attempts to increase the formalization of a task when these conditions are not met, efficiency is likely to decrease.

Formalization can be developed at two levels [31]. In internal organization structures, formalization is increased by developing and enforcing rules and standard operating procedures. In external structures, formalization increases as the procedures to be followed by suppliers are spelled out in more detail, e.g., by means of a legal contract.

Formalization becomes a primary characteristic of the standard process system. However, it is worth noting that the formalization concept is not exactly the same as standardization despite both terms being used interchangeably in some works. Standardization consists of unifying the way in which the activities of a certain process are developed so that process execution is independent of internal variables (i.e., who executes the activities or when) and external variables (i.e., customer name or due date). Formalization has more to do with documenting the process, that is, writing the activities making up the process in the appropriate format as text (procedure), graphically (process model) or both. Obviously, even though these two concepts are closely related, a process can be standardized in an extreme case, but not formalized.

The importance of documenting processes for their formalization comes over clearly on some of the scales used to assess the formalization level of processes. The existence of "written" procedures is favorably scored on several of these scales (see the examples in Genchev et al. [28] (p. 248)).

Obviously, the fact that a company is business process management oriented helps it to make progress with its formalization level and to the extent that its processes are identified, described, documented or modeled. Likewise, quality certification systems, which promote the development and use of quality procedures in companies, can act as catalysts to formalize processes [29].

RL formalization will allow a single document to be obtained for the entire organization, which can be conveniently updated in successive improved versions. Therefore, formalization as both procedures and models reduces complexity, favors the global vision 
of the process and allows potential weaknesses and the immediate application of corrective actions to be identified [32] to, thus, constitute the basis to continuously improve processes.

Likewise, having a single document for each process allows workers' points of view to be unified and generates confidence in how things should be performed. This, in turn, facilitates the identification of the process' objectives and the definition of the corresponding key performance indicators (KPIs) to control their compliance. Precisely along these lines, Huscroft et al. [24] propose the performance metrics in an RLP to be standardized across the firm and to directly correspond to the firm's RL goals. Therefore, future research could focus on developing standards and establishing metrics to control the degree to which processes meet standards.

Control differs from formalization because it focuses on ensuring standard process system functioning in an internal firm context, although formalization level is indicative of how much control a given organization has over its returns management practices. Hence the control issue is associated with the formal development and implementation of written RL-related policies, rules and procedures [28]. Bowersox et al. [67] contend that formalized control mechanisms allow logistics operations to offer advantages in efficiency terms.

Internal operations are formalized and, therefore, made more efficient by establishing workplace rules or standard operating procedures. As RLP becomes more formalized and explicitly defined, employees more easily understand and execute these procedures. Conversely, when processes are informal, and given the excessive amounts of returns encouraged by liberal policies, the potential for confusion arises and variability in reverse logistics handling may result. Here formalization can also help incentive systems to develop and grow. If employees understand how the RLP is supposed to work, and are informed about how to operate it more efficiently, proper incentives and their performance metrics can be employed to ensure that the RLP is appropriate [68]. Obviously to accompany such actions, the importance of education, training and developing the skills of those workers involved in recovery activities, and as important enablers in developing RL systems, should not be forgotten [29].

Therefore, RLP formalization can provide a solid structure to both achieve substantially different capabilities and enhance performance [69]. Formalization has been recognized as a key element for developing the ability to exploit a firm's capabilities [70,71], and is a key attribute in those firms considered to be leading-edge companies in logistics practices terms [16]. Furthermore, as the RLP becomes increasingly formalized, firms are believed to become more efficient in returns handling by standardizing repetitive activities and transactions [31], and also because formal rules and procedures eliminate the need to treat every event as a new decision. When handling returned products, improved efficiency can be translated into reclaimed value, which improves the firm's bottom [72]. Formalization can even help to find innovative approaches that can be developed to bypass the standard formats used for the original RLP and to apply special decision rules or policies to returns [34]. For example, policies can be developed to speed up the returns authorization process for those customers who return merchandise.

In short, a formalized approach can enhance performance, eliminate ambiguity, clarify priorities [73] and encourage process innovation [26], but also reduce costs, streamline operations and enhance the overall efficiency and effectiveness of logistics [67]. Han and Ponce-Cueto [60] summarize the main benefits for the companies that adopt formalization and add the following to the above aspects: better control of operations, reduced uncertainty and improved service level.

Therefore, if we consider that process formalization is generally believed to be related to firm performance [30], and given the massive volumes of returns that modern companies face, lack of formalized RL programs or processes is somewhat surprising [16]. Even though RL volumes and demands may be difficult to predict, RL system components (involving bringing back products or arranging an alternate disposition) can be routinized. Actually the RLP should not be treated as a sporadic process but as a regular process [74]. Thus, 
given the very nature of $\mathrm{RL}$, it would seem the ideal candidate for developing formalized handling methods [16].

Some potential disadvantages of formalization should also be acknowledged, such as less operational flexibility (as it is mandatory to follow procedures and rules), stifled innovativeness, cumbersome knowledge transfer and the possible generation of paperwork and lots of administrative tasks $[67,75]$. Notwithstanding, research into formalization in logistics suggests that the benefits outweigh the potential drawbacks [67].

As a brief summary, it should be noted that the advantages of RLP formalization seem obvious but, as far as we know, no work in the literature offers an overview of the generic RLP in sufficient detail that can serve as a reference for companies to formalize their own RLP. In order to bridge this gap, a reference model that can be used to the RLP formalization is presented.

\section{The Proposed Reference RLP Model and the Adaptation Methodology}

A reference process model is a model of day-to-day operations in a given domain such as SC management or logistics. Reference process models are intended to be configured in a specific context to lead to individualized process models. One major benefit of configuring a reference process model for a given project, as opposed to building a new model from scratch, is the ability to reuse and build on proven practices [76].

The reference RLP model (RM-RLP) proposed in this paper aims to guide companies to formalize their own RLP from a generic or reference RLP model.

First, the activities composing the RM-RLP are described as a procedure based on the insights gained from the literature review about which activities make up the RLP, but they provide more details to facilitate its employment by companies and to increase its usefulness. This textual description is perfectly supplemented by the reference model and can also guide companies to prepare their own documents to, thus, reinforce RLP formalization.

Second, the RM-RLP based on the BPMN 2.0 language is proposed [61].

Finally, to facilitate RM-RLP use, a simple 3-step methodology is proposed to guide users in the process of adapting the RM-RLP to each company's particular case.

Two assumptions to formulate the RM-RLP have been used: (a) the users of the reference model should sufficiently know the BPMN 2.0 modeling language to correctly interpret it and make the corresponding modifications or adaptations; and (b) the different activities considered in the reference model must be assigned to a person in the company responsible for their execution although, due to the great variability existing in the companies regarding this matter, in the proposed reference no assignment was carried out.

\subsection{RLP Activities Description (Procedure)}

From the framework used to classify RLP activities, as indicated in the Background section, three groups of important activities, or macro-activities, must be considered in the RLP, which are called Step (1) collection and transport, (2) inspection and sorting, and (3) disposition. Each one is explained below.

Step 1. Collection and transport.

The RLP begins when the customer contacts the company by telephone, in person or via electronic communication. Once the RLP is underway, the first question that the company must consider is whether or not to proceed with a return, which is the first phase in which DD is applied. In this case, the company can make a first assessment of whether it should or should not treat the product and, therefore, follow the process. If the company decides to not treat the product, the next question is to know if it is necessary to compensate the customer so that, if this were the case, it must make compensation before ending the process.

When the company decides to deal with the return or recovery, it should consider whether the customer needs a replacement product. If so, the product collection transport should also be used to deliver the replacement product. 
The next question that the company must ask is whether the customer needs onsite intervention, which is often the case with, for example, large appliances. If so, the company should carry out an onsite intervention of the product to determine whether or not the product can be repaired. Regardless of the product being repaired or not, the company must consider the possibility of compensating the customer to cover any inconvenience caused. If the product can be repaired, the process ends. If the product cannot be repaired, the company should also consider treating the product, or not, in its facilities.

When a decision is made to not treat the product, the company analyzes the customer compensation issue which ends the process. If instead the company decides to treat the product, it transports it to its facilities and the process continues.

When it decides to treat a product, but no onsite intervention is required, the company must consider whether transportation is required to collect the product to bring it to its facilities. If so, the delivery options (and collection if applicable) are analyzed, such as marking the route, transport type, date, etc. Finally, the date and delivery conditions (and collection if applicable) are negotiated with the customer. If no agreement is reached with the customer and treatment cannot be performed, the process ends after assessing the need to offer compensation.

When the company has the customer's consent to collect the product, transport is reserved, the route is assigned and the corresponding merchandise is received by the company, which inspects it. This is how the first RLP stage ends.

Step 2. Inspection and sorting.

As soon as the company receives the product, it is inspected and evaluated to determine the most appropriate disposition. The customer is informed about the disposition that can be made, lead times and the possible financial compensation in the event of noncompliance. Thus, with the DD, the company decides if the product is suitable for reuse or resale, if it must intervene to place it back on the market or if its components can be used.

When the company makes a DD about the product or its components, the second stage ends and the third and final stage begins.

The DD is considered one of the most important decisions in the RLP [51] for its impact on the flow of materials and the operations performed throughout the SC [77,78], and also for its importance for sustainability of operations [79].

Given the criticality of this DD for SC operations and their sustainability, it is worth completing this section by describing two fundamental aspects that must be contemplated to succeed with the DD: (a) the time in which these decisions must be made and (b) the information required for them.

The two key times in which the DD should be made are described below:

1. The customer contacts the company.

When the customer contacts the company in person, or by phone or email, a decision must be made as to whether the company deals with the return or recovers the product. DDs are not generally made at this time. The customer may not even be served by the decision maker, who decides about product treatment. The important point in this stage is to decide whether to start/continue with the RLP or to leave it.

2. The product arrives at the company's facilities.

An inspection is made to decide the most suitable final disposal option in each case. To make the DD, it is necessary to specify not only all the data provided by both the customer and the company about the product, but also any other related aspect. Based on all the collected information, the decision maker determines the product's disposition from among the following three options: (a) return the product to the market as it is, (b) intervene in it to place it back on the market or (c) disassemble it to make the most of its components. These three options are explained in more detail below:

a. Direct product reuse/resale. If it is determined that the product can be placed back on the market as it is, the company must decide whether to put it up for sale via 
a traditional or secondary channel or an outlet type at a lower price or to even donate it.

b. Intervening in the product. Having determined that the product needs intervening to place it back on the market, it might have to be transported again to be intervened. When it arrives, product intervention is made (repair, refurbishing or remanufacturing).

c. Using components. If the most appropriate disposal option is to use its components, the product must be disassembled to obtain them. Then the final disposition of each component can be assessed according to its specific state. First, a decision is made to see if components are in perfect condition to be used or recycled. If none of these alternatives are feasible, components are disposed of in a controlled manner by incineration or landfilling.

The other key DD aspect is the employed decision-making information. The information type is divided into two blocks, as described below: customer and company information.

1. Customer information.

a. Current product status. It is essential for the company to obtain as much accurate information as possible about the current product status to catalog it for disposition purposes. Based on the information provided by the customer, the company can classify the product in four ways: in perfect condition, slight or superficial failure, serious failure or non-specific condition.

b. Purchase date. It is essential to verify the purchase date to corroborate the corresponding warranty period and to agree about who should pay the possible treatment or payment costs for product recovery.

c. Product purchase cost. These data might also be essential for determining product disposition. With very low-cost products, it might not be worth the company collecting them for treatment. Perhaps the best option is to compensate the customer by giving back the amount paid for the product or sending a new one.

d. Place where it is collected. The place where the product is located determines collection costs and, therefore, influences the operation's economic profitability, as well as its environmental and social impacts.

2. Company information.

a. Collecting product data. Apart from verifying the accuracy of the data provided by the customer, the company must collect as much information as possible about the product to consider its recovery and treatment.

b. Transportation options. Depending on where the product is located and its characteristics, the company must assess the different options of transport between the company and the customer to opt for the best disposal alternative.

c. Current demand of product/components. Another important piece of information that the company must collect is the current demand for each product and/or its possible components because it influences the best disposal alternative choice.

d. Legislation on the product and its components. This legislation is crucial to avoid possible sanctions or to obtain some type of incentive for its recovery and/or treatment.

Step 3. Product disposition.

This last step covers all those activities that take place, from the time a decision is made about the treatment/disposition to be applied, to the time the product is delivered back to the customer or if its components are to be used or properly disposed of.

If the company decides to reuse or resell the product as it is, the intention is to place it at the customer's disposal as quickly as possible by organizing the necessary transport to do so. 
If the company opts to intervene in the product, this task might need to be performed in different facilities to those where the product is located, in which case the corresponding transport to other facilities to intervene in the product is organized.

Intervening in the product is made to the extent agreed on and according to the appropriateness of each alternative (repair, refurbishment or remanufacturing). After this treatment, the company may consider further interventions if the expected outcome is not obtained. Otherwise, the product is sent back to the customer as soon as possible, as in product reuse cases.

When the alternative to make good use of components, the next activity is to disassemble the product. At this point, each component status is evaluated to decide on selling it or using it as raw material for other products if it is in good condition. If it is not in good condition, the next option is to recycle it and organize the corresponding transport if necessary. If a component is not in good condition and cannot be recycled, the company disposes of it in a controlled manner by resorting to companies that specialize in incineration or landfills, and by organizing any corresponding transport.

\subsection{The Reference Model Proposal for RLP Formalization (RM-RLP)}

After explaining the RM-RLP in detail, we now go on to present its modeling in the BPMN 2.0. language. To facilitate its understanding, we present a simplified figure (Figure 1) that highlights colors to denote the three model areas corresponding to the three macro-activities identified in the background section (1. Collection and transport, 2. Inspection and sorting, 3. Product Disposition).

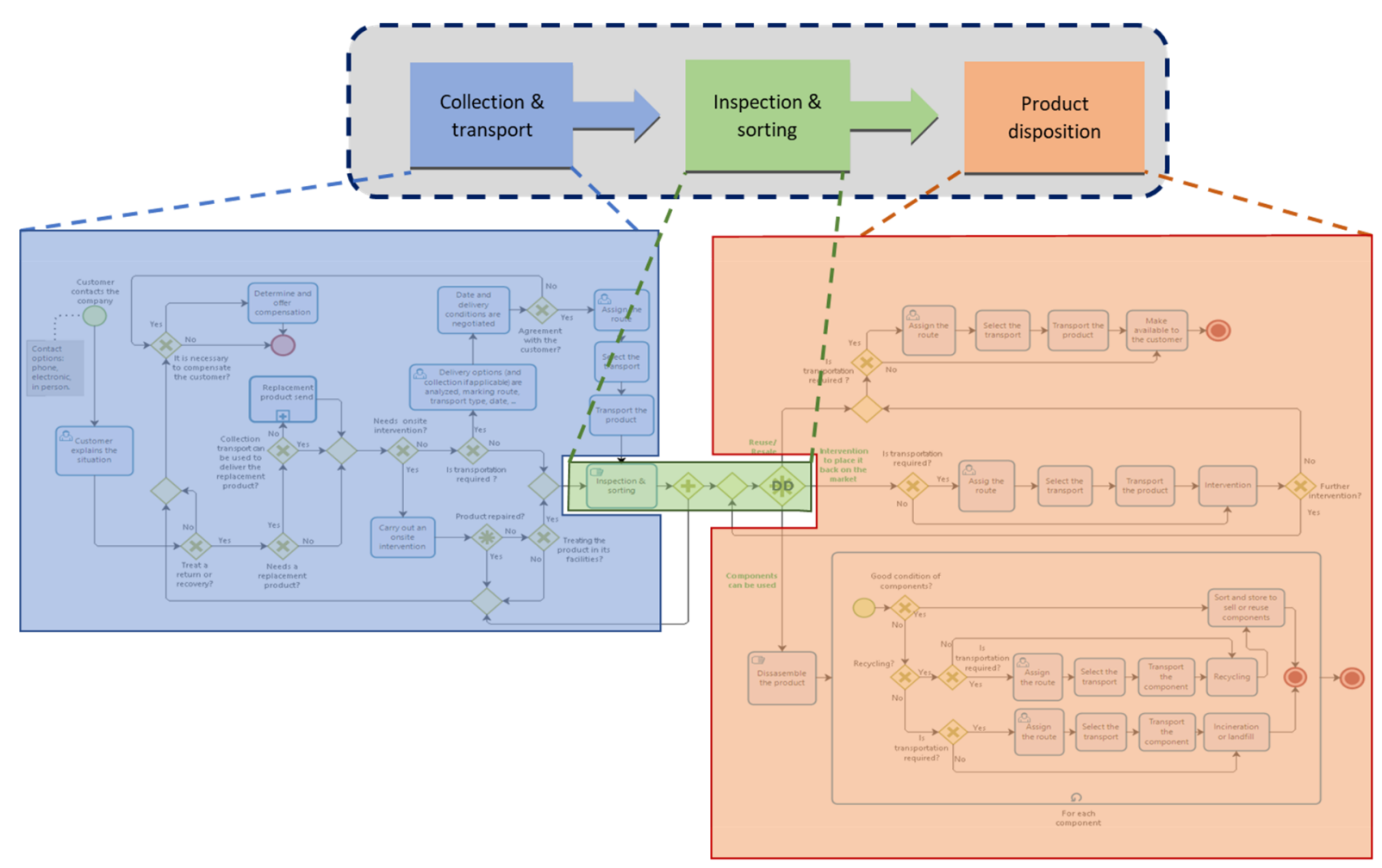

Figure 1. Relationship between three main principal RLP steps and the reference model proposed.

Although the above figure does not depict the RLP activities in detail, its intention is to show the correspondence between the proposed reference model and the three main macro-activities employed within the framework in the background section.

The following figure (Figure 2) shows the proposed RM-RLP: 


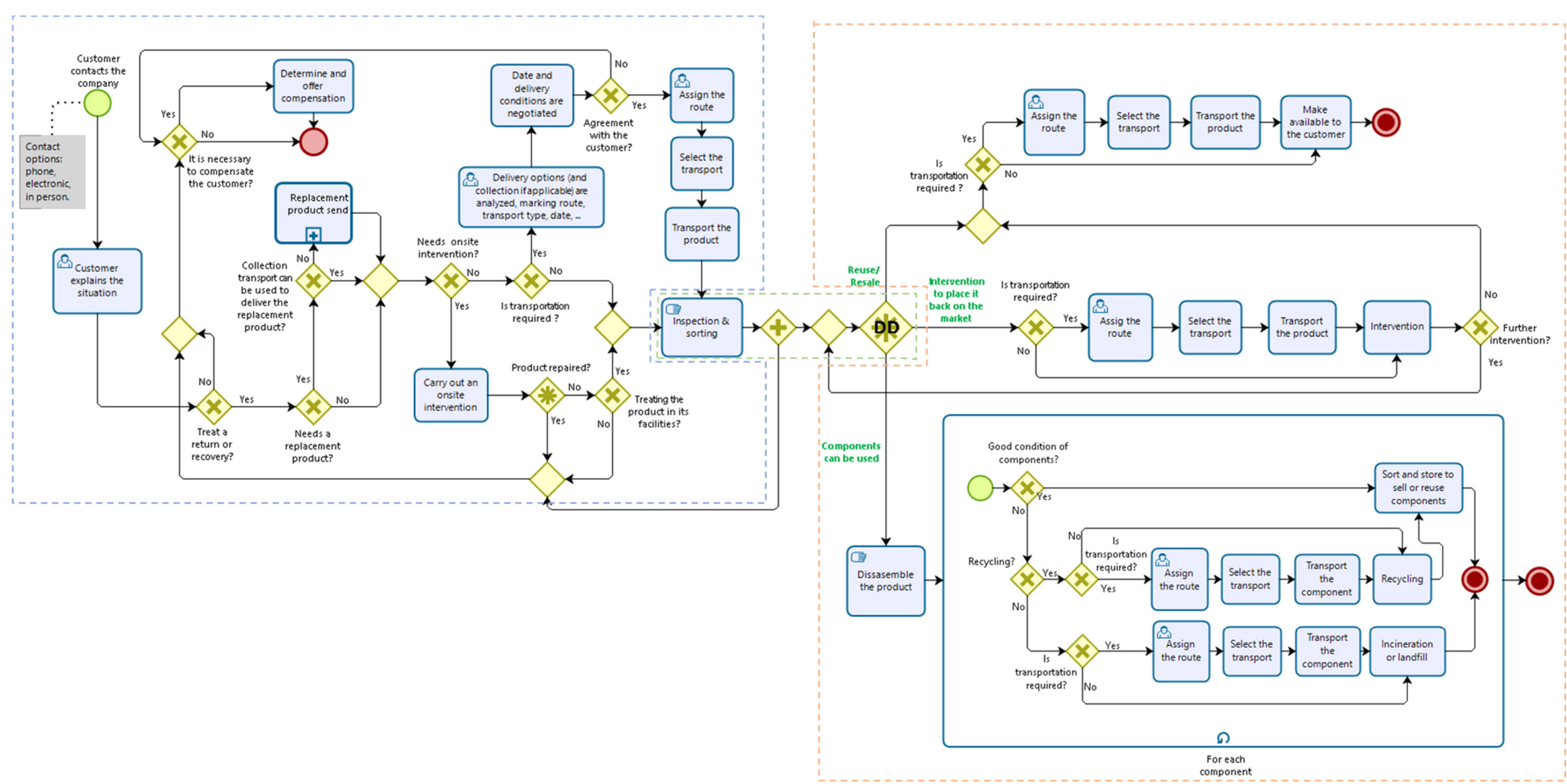

Figure 2. Reference model proposed (RM-RLP). 


\subsection{Methodology to Adapt the RM-RLP}

This section describes the methodology followed to adapt the RM-RLP to a specific RLP case. This methodology comprises three main steps, which are shown in the Figure 3 below:

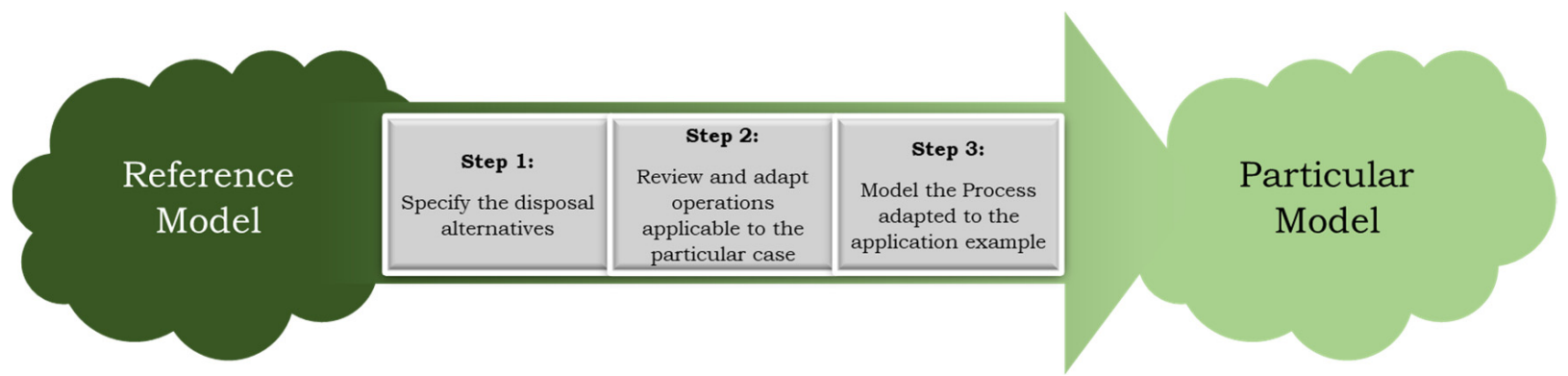

Figure 3. Graph of the methodology to adapt the RM-RLP to a particular case.

These three steps are explained below:

Step 1 . Specify the disposition alternatives.

The RM-RLP contemplates all the possible product disposition alternatives [51] to apply this model to any casuistry that may arise in a company. To this end, the first step to adapt the model is to specify the feasible disposition alternatives in each given case in which the disposition alternatives are adapted, eliminated or modified as appropriate. Using the table below Table 1) is proposed to facilitate this step, which shows the eight possible disposition alternatives:

Table 1. List of all the possible disposition alternatives that can be considered in Step 1 of the RM-RLP.

\begin{tabular}{ll}
\hline \multicolumn{1}{c}{ Disposition Alternatives } \\
\hline 1.- Reuse \\
\hline 2.- Repair \\
\hline 3.- Refurbishing \\
\hline 4.- Remanufacturing \\
\hline 5.- Cannibalization \\
\hline 6.- Recycling \\
\hline 7.- Incineration \\
\hline 8.- Landfilling
\end{tabular}

This table indicates the alternatives that can be applied to the particular model, and those that cannot, by means of two symbols that can be placed in the first column:

$\checkmark$ Alternative that can be applied.

$\boldsymbol{x}$ Alternative that cannot be applied.

Step 2. Revise and adapt the applicable activities to the particular case.

In order to follow this step, users applying RM reproduction that is either printed or comes as a computer support to allow editing is recommended. First, any disposition or treatment alternative and associated activities that cannot be applied according to Step 1 should be removed from the model. To facilitate this step, a figure (Figure 4) was created to identify the activities corresponding to each disposition alternative.

Second, it is necessary to also identify and remove any other possible activities initially indicated in the RM-RLP that cannot be applied, as well as marking those that are executed differently to the way proposed in RM. To do so, completely revising MR by following all the possible flows and ramifications is recommended to not overlook anything and for the particular model to represent its normal execution as reliably as possible. 


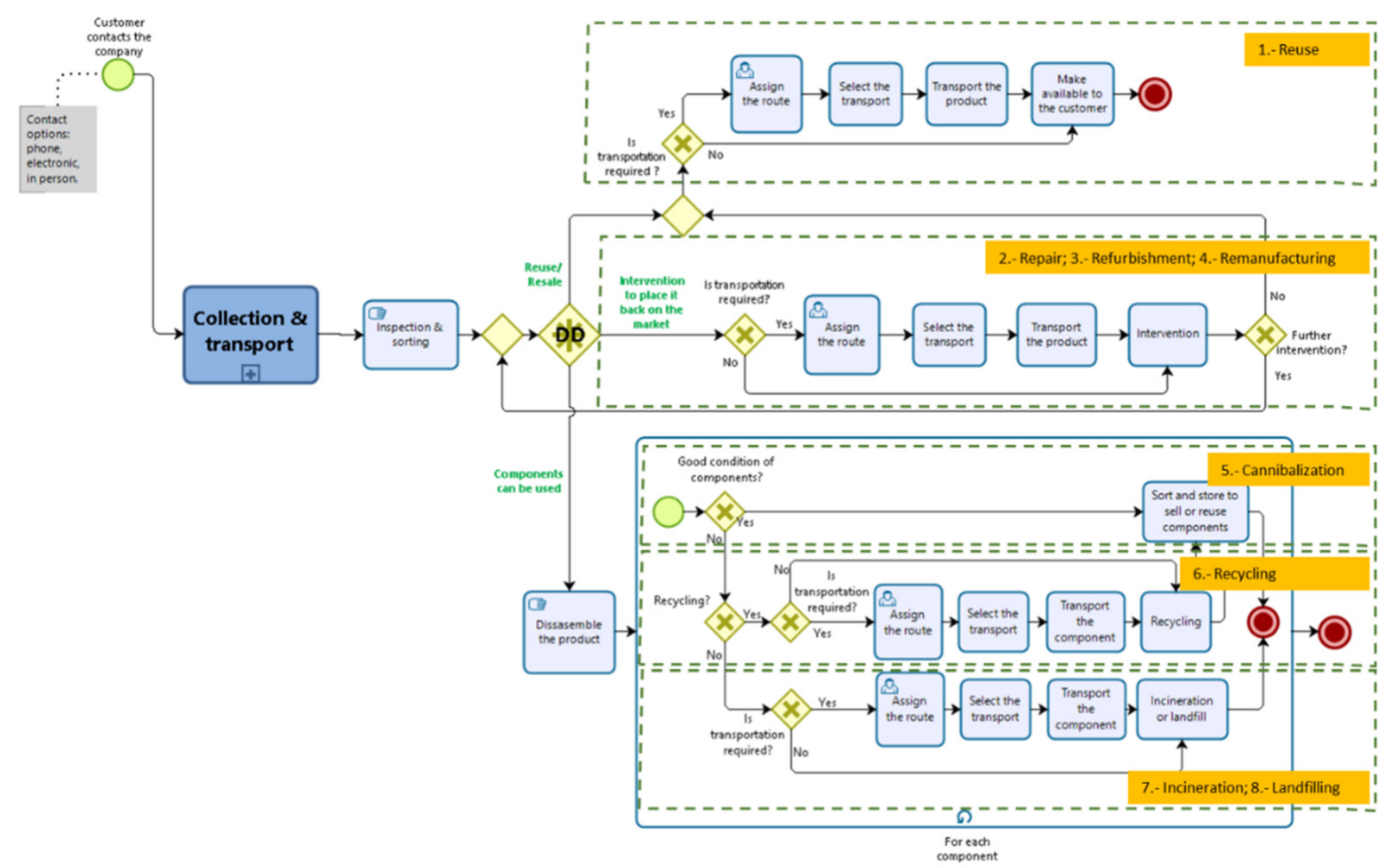

Figure 4. The RM-RLP proposed with activities to each disposition alternatives.

Step 3. Model the RLP adapted to the application example.

After identifying all the activities that need to be removed from RM, the next step is to build a new model from scratch with the remaining activities by including the corresponding modifications and revising the connections between the resulting activities to see if they are correct. Evidently, the outcome from the previous step should be taken as a reference. Creating the new particular model in the BPMN language so that it is coherent with the RM-RLP is recommended.

\section{Example of a Relaxing Chairs Application to a Closed Loop SC}

EU State Members throw away around 10 million tons of furniture every year. Despite having improved tasks to reuse products in the EU with new "green policies", between $80 \%$ and $90 \%$ of furniture waste in the EU ends up being landfilled or incinerated according to European Furniture Industries Confederation [80]. Circular flow activities are still minimal, with a recycling rate close to $10 \%$ and remanufacturing below $2 \%$ [81].

Reuse activity in the sector is also low and mainly takes place in secondhand shops or charities with social objectives. In this context, Spain is the first European country to establish a compulsory national reuse objective by setting a target of $50 \%$ waste of any kind to be recycled or prepared to reuse it by means of PEMAR 2016-22 (State Waste Management Framework Plan). PEMAR specifies that a minimum $2 \%$ waste shall be prepared to be reused and furniture waste is clearly susceptible to be resold.

One of the main barriers for the furniture sector to set up a circular flow is lack of information on, and standardization of, disposition alternatives [81]. Formalizing RL processes according to a systemic approach that allows these problems to be integrally viewed can facilitate the transformation of firms toward a more efficient and sustainable model.

With the specific case of relaxing chairs, recovery, classification and the subsequent disposition of returned or recovered products compose a closed-loop SC in which one sameproduct manufacturing company is in charge of collecting, inspecting and then disposition. In this case, recovering the type of product to be worked is complicated because it is made up of four basic, very different components, and degrees of hazardousness: wood, 
fabrics/leathers/plastics, metals and electric/electronic components. Obviously, all this makes the recovery task more complex than furniture made only of wood.

The product in this case would be such as that shown in the image below (Figure 5):
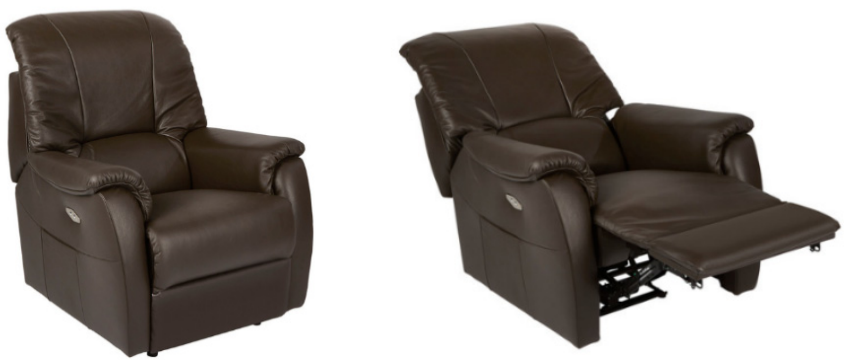

Figure 5. Type of product treated in the application example.

RL products, or recovered products in this particular application example, arrive mainly due to incidences or claims in sales or when furniture is no longer left on show. Each RL case that arises with such products corresponds to either one of these categories:

- Product in perfect condition. Here the customer does not want the chair for reasons other than product status. So, the chair is placed on the market again because it is in perfect condition.

- Product not in perfect condition. When a product is returned to the company and is not in perfect condition (damaged during transport, failing mechanism, torn fabric or some other flaw, spoiled from being left on show, etc.), three different disposition options apply:

- The chair can be sold directly exactly as it is on a secondary outlet-type market.

- It can be refurbished to place it on the market again as a new product.

- It can be disassembled in an attempt to reuse its valid components in new models and to recycle its invalid components.

In the company under study, the volume of returns and recoveries is much smaller than that of its sales and is residual. Thus, not enough attention is paid to the RLP. Some characteristics of its RLP are:

- It has no suitable or identified location to receive, inspect and store returned or recovered products.

- Both the RLP and the DD are not documented and are, thus, not formalized. The steps taken or activities performed vary with each recovered product depending on the worker in charge of the process.

- No relative information is available about each RL product, or about possible disposition alternatives, as regards its/their impact on sustainable dimensions (economic, environmental and social).

For the company under study, today RL is a problem rather than a competitive advantage or improvement opportunity, and it has the following consequences:

- Not putting material resources to best use to reduce costs and to make more profits.

- The company's image suffers given its lack of credibility and swiftness to respond to customers.

- It does not plan sustainable objectives in RL operations, which consequently endangers complying with environmental legislation.

In this context, formalizing RLP can help to document the activities that must be performed, establish decision-making criteria, cut customer response times and, in short, be more efficient. These improvements could be highly appreciated by the company under study as it is located in the province of Valencia, in a furniture cluster, where the levels of competitiveness are very high. In order to achieve these improvements, the methodology 
to adapt the RM-RLP is applied to this specific case following the steps set out in the previous section:

Step 1. Specify the disposal alternatives

RM provides all the possible casuistry of the RLP, and its adaptation to this particular case consists of selecting from the possible casuistry those alternatives that apply to this case. We now go on to revise the alternatives to verify which are considered, or not, to treat relaxing chairs in the company under study.

1. Reuse. Not intervening on the product to place it on the market again.

As little intervention as possible is made on the chair to place it back on the market again. The idea of this alternative is to incur few maintenance expenses (cleaning, labeling, packaging, storing, etc.). In this application example, two different reuse types are considered depending on the sales channel:

- Reuse/resale directly on the primary market. The aim of this alternative is to once again place the chair to the public's disposal as a new product via the usual channel. This is the most profitable and prioritized option for the company because it implies fewer interventions (less environmental impact) and more income (more economic profitability).

- Reuse/resale directly on the secondary "outlet" market. In such cases, chairs are still suitable for use, but their quality standards are not the same as those of new products which is why a secondary market is resorted to. So, this product is placed on the market again via a different channel to the previous case and at a considerably lower price.

2. Repair. Intervening on the product to place it on the market again.

Relaxing chairs are not repaired by the company under study because the degree of intervention on recovered products is higher and they are left as new by refurbishing.

3. Refurbishing. Intervening on the product to place it on the market again.

In this case, chairs are not in perfect condition and must be intervened on to refurbish them and be able to place them on the primary market as new products.

This process may vary according to the intervention that products require. Here the refurbishing cost (transport, intervention, storage, etc.) and the sale price on the market must be carefully measured for them to be profitable. This means that refurbishing merges with repair and remanufacturing. However, perhaps the term refurbishing is more suitable because, in this particular case, it really revises the whole product, and any component that is not in perfect condition tends to be replaced with a new one so that the product can be placed on the market again with at least the same price and quality as at the beginning.

4. Remanufacturing. Intervened on the product to place it on the market again.

The intervention made by the company on the recovered product to place it on the market again is considered to be refurbishing, and not remanufacturing, because the components that do not work properly are not remanufactured but are replaced with new components.

5. Cannibalization. Intervening on the product to reuse its components.

First the product is disassembled to work with its components and to reuse them to be employed in other products. Their basic structure, motor and upholstery can be employed to make new relaxing chairs.

6. Recycling. Intervening on the product to reuse its components.

Relaxing chair components can be completely recycled. So, their basic structure, motor and upholstery are left in a waste facility where specialized outsourced firms are in charge of collecting and disposing of them. With upholstery, leather is basic for activities such as leatherwork or falconry and can, therefore, be "easily" sold to be used as raw material for new components (wristbands, bags, wallets/purses, gloves, etc.) 
7. Incineration. Elimination without recovering value.

All product components are reused by cannibalization or recycling or are incinerated if there is no option available to previously recover their value.

8. Landfilling. Elimination without recovering value.

As in the previous case, all product components are reused by cannibalization or recycling or are landfilled if there is no option available to previously recover their value.

After reviewing all the disposition alternatives, the table below (Table 2) shows which are applicable and which are not:

Table 2. Disposition alternatives that apply to the application example.

\begin{aligned} & \hline \multicolumn{1}{c}{ Disposition Alternatives } \\ & \hline $\begin{array}{l}\text { 1.- Reuse } \\ \text { (a) Primary market } \\ \text { (b) Secondary market }\end{array} \\ &$\hline$\times$ 2.- Repair \\ & \hline$\checkmark$ 3.- Refurbishing \\ & \hline$\times$ 4.- Remanufacturing \\ & \hline$\checkmark$ 5.- Cannibalization \\ & \hline$\checkmark$ 6.- Recycling \\ & \hline$\times$ 7.- Incineration \\ & \hline$\times$ 8.- Landfilling \\ & \hline\end{aligned}

Step 2. Review and adapt operations applicable to the particular case.

In this second step of the methodology, RM is revised based on the application example in such a way that those activities not to be performed can be eliminated, others can be added or those considered appropriate can be modified to formalize the process more realistically. So, the main changes made to the RM-RLP to adapt it to the particular model of the present application example are the following:

1. The reuse alternative is extended by including the decision about what type of reuse is to be applied: on the primary or the secondary market.

2. Any transport activities before product intervention are eliminated because this is performed in the same facilities where the DD was made, unlike those set out in the RM-RLP.

3. The incineration and landfilling alternatives are eliminated.

Step 3. Model the process adapted to the application example.

In the third and last step of the methodology, the particular process is modeled by including all the modifications in relation to what is indicated in the previous step. The particular RLP model is shown below (Figure 6) that corresponds to relaxing chairs. The following main changes were made to the model in relation to the RM-RLP, denoted by a dashed, red-lined square. Dashed red-lined square number 1 corresponds to the extended reuse alternative, square number 2 corresponds to adapting previous transport to the intervention and square number 3 denotes the elimination of the incineration and landfilling alternatives. 


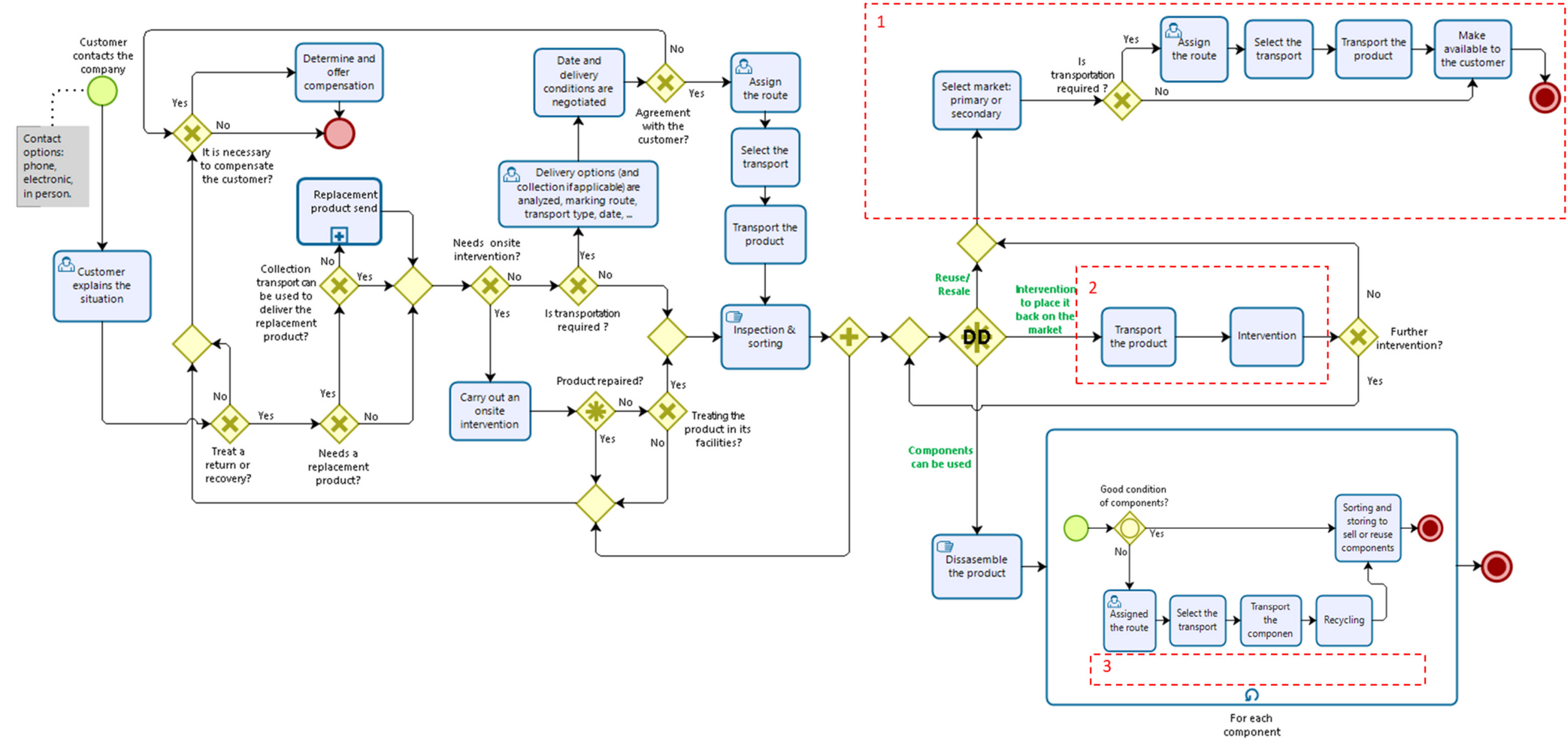

Figure 6. The particular RLP model. 


\section{Validation of the Proposed RM-RLP}

The proposed RM-RLP is intended to help companies formalize RLP. One way to validate the usefulness of this tool would be to compare it with other similar tools, perhaps by defining a framework for comparison, probably based on its capabilities. However, as the literature review revealed, no similar tools have been found to support such a comparison.

Another way of assessing the usefulness of the proposed tool is through the direct opinion of its users, in this case the company under study. In this regard, it should be noted that the company managers and operators involved in the RLP say that the tool is very useful and easy to apply, and that it has saved them a lot of time in the process of formalizing RLP, even though it was necessary to carry out some training sessions on the BPMN 2.0 modelling language with all the users involved. This is an opinion that we obviously find very valuable and gratifying, but it is still an opinion with a corresponding degree of subjectivity.

A third way to assess the usefulness of the proposed tool, although more indirect than the previous ones, is through the quality of the result obtained using it. That is, if the RM-RLP achieves the formalization of RLP, and this formalization works correctly and provides the expected advantages, then it could be inferred that the proposed tool for the formalization of the RLP is useful. Given the aforementioned drawbacks of the first two, this third way will be the one to be explored in this section.

To this end, it is worth briefly recalling the advantages of formalizing RLP that have been mentioned throughout the paper. Some of these advantages are general, such as: benefits the organization as a whole, is an important enabler for developing the RL system, enhances performance or improve firms' efficiency. Others, however, are more concrete, such as: allows firms to properly manage customer expectations as regards returns, eliminates ambiguity and clarify priorities, reduces complexity and speeds up decision making.

In order to assess the usefulness of the proposal, the focus has been on the more concrete advantages. Thus, we understand that the proposed RM-RLP will be validated as a useful tool if it helps the company under study to formalize its RLP and benefit from its (concrete) advantages. We will now proceed to carry out this verification.

\subsection{Hypotheses' Formulation}

Firstly, we have seen that, frequent pauses in the RLP to decide what to do in the face of ambiguous activities or to define priorities, increase its duration. In the same way, high complexity and decision making without clear criteria require more effort from workers and also lengthen the duration of the process. Therefore, a decrease in the duration of the process will be a symptom that formalization has improved the RLP and, therefore, the first hypothesis that we want to demonstrate to justify the advantages of formalization is:

Hypothesis 1 (H1). Formalization of the RLP reduces its duration.

Several important decisions are made in the RLP, but there is one that has a direct impact on the customer: the decision of whether or not to return or recover the product. This decision, in addition to conditioning the rest of the process, makes it possible to provide a response to the customer, decisively influencing the company's image. If the process is not formalized, this decision may not be well defined and may be difficult to make, especially when the number of treatment alternatives for this product is high. In this case, the response time will be long, requiring several interactions with the customer. Obviously, this time lapse is included in the total duration of the process considered in the previous hypothesis, but it represents a different aspect of sufficient relevance to formulate a second hypothesis:

Hypothesis 2 (H2). Formalization of the RLP reduces customer response time.

On the other hand, a high complexity in the process and decision making without clear criteria will require a greater effort from the workers involved in the RLP and, therefore, 
will generate a feeling of discomfort and uncertainty. This feeling of uncertainty will often result in consultation with higher-ranking personnel (i.e., section chief) or other colleagues who may have more experience, leading to interruptions and the consequent loss of efficiency in the process and in the company as a whole. As the process is not formalized, the solutions adopted in each case are not recorded and inefficiencies will be numerous and recurrent. In this sense, the third working hypothesis is:

Hypothesis 3 (H3). Formalization of the RLP increases the level of autonomy and confidence of workers.

Next, we will try to validate these working hypotheses with real data obtained from the application example, which will make it possible to demonstrate, and even quantify, the interest of the formalization of the RLP for the specific case in question. To this end, three KPIs have been defined that correspond to the three hypotheses as indicated by the numbering used to designate them. These three KPIs represent all the specific advantages found in the literature review. These KPIs are explained below:

- (KPI-1) RLP duration: Quantifies the time in minutes that elapses from the time the customer contacts the company until just before the product is dealt with. As there may be time differences depending on the treatment the product is to receive, this KPI has been subdivided into three, one for each type of treatment considered, as follows: (a) the product is made available to the customer, (b) the product reconditioning intervention is started or (c) the components are deposited in the recycling or cannibalization container.

- (KPI-2) customer response time: Quantifies the time in minutes that elapses from the time the customer contacts the company until a definitive answer is given regarding the treatment of the product. This KPI is really a fraction of the time represented by KPI-1, so there is a clear correlation between them.

- (KPI-3) level of autonomy and trust of workers in RLP: Quantifies the perception of workers regarding the autonomy and confidence they have during the execution of the RLP. It is measured in values from 1 to 5 , according to the Likert scale; values close to 1 indicate a perception of low autonomy and trust, and values close to 5 , a perception of high autonomy and trust.

\subsection{Experiments Methodology}

The data concerning these three KPIs started to be collected in October 2019, in the framework of the PhD thesis pursued by one of the authors of this work, and were finished being collected in May 2021. Work was ongoing to formalize the process for approximately two weeks, including in this time some training sessions on the BPMN 2.0 modeling language with all users involved, and the results of the formalization were implemented in July 2020. In this period, from the beginning of the study to the time of formalization implementation (10 months), named the pre-formalization period, there were a total of 10 recoveries. In the period from the time of formalization to the end of May 2021 (9 months), referred to as the post-formalization period, there were a total of 10 recoveries.

Much of the data in this study has been generated in a pandemic situation. This situation has altered the pattern of demand for almost all types of products, although the demand for recliners has not been one of the most affected; based on the information available to us, it appears to have increased slightly last year. This may have also led to a slight increase in returns and recoveries, but we believe that this should not significantly affect the results of this study.

The data were collected by four operators who were dedicated to the management of the RL activities for the duration of the study. These four operators have been previously made aware of the importance of data quality for this study and have been trained and provided with the necessary tools to obtain the time data (KPI-1 and KPI-2) through timekeeping. The data related to autonomy and confidence (KPI-3) were collected using a 
six-question form based on a Likert scale and designed for this purpose. This form was filled in at the end of each iteration of the RLP using the Google forms application.

\subsection{Data Collection}

The following tables (Tables 3 and 4) show the data obtained for the three KPIs corresponding to the pre-formalization and post-formalization periods of the RLP, respectively. The numbered columns (1 to 10) show the values obtained for each of the recoveries. For KPI-1, three rows have been used (KPI-1a, b and c), according to the different final product arrangements considered in this application example. Two other rows show the results for KPI-2 and KPI-3.

Table 3. Data obtained during the pre-formalization period for the three KPIs considered.

\begin{tabular}{|c|c|c|c|c|c|c|c|c|c|c|c|}
\hline & & \multicolumn{10}{|c|}{ Returns in Pre-Formalization RLP Period } \\
\hline & & $1^{\mathrm{a}}$ & $2^{a}$ & $3^{a}$ & $4^{\mathrm{a}}$ & $5^{\mathrm{a}}$ & $6^{\mathrm{a}}$ & $7^{\mathrm{a}}$ & $8^{\mathrm{a}}$ & $9^{a}$ & $10^{\mathrm{a}}$ \\
\hline KPI-1 & Process duration (min.) & 155 & 184 & 355 & 420 & 155 & 205 & 165 & 105 & 125 & 123 \\
\hline$K P I-1 a$ & (a) Product disposition & 155 & & & & & 205 & 165 & & & 123 \\
\hline$K P I-1 b$ & (b) Intervention & & 184 & & & 155 & & & 105 & 125 & \\
\hline KPI-1c & (c) recycling/cannibalization & & & 355 & 420 & & & & & & \\
\hline KPI-2 & Customer response time (min.) & 65 & 57 & 149 & 265 & 120 & 149 & 72 & 68 & 77 & 81 \\
\hline KPI-3 & $\begin{array}{l}\text { Autonomy and confidence of workers (1-5 } \\
\text { points) }\end{array}$ & 2.33 & 2.5 & 2 & 2 & 2.5 & 2.5 & 2.66 & 2.33 & 2.5 & 2.66 \\
\hline
\end{tabular}

Table 4. Data obtained during the post-formalization period for the three KPIs considered.

\begin{tabular}{|c|c|c|c|c|c|c|c|c|c|c|c|}
\hline & & \multicolumn{10}{|c|}{ Returns in Post-Formalization RLP Period } \\
\hline & & $1^{\mathrm{a}}$ & $2^{a}$ & $3^{\mathrm{a}}$ & $4^{a}$ & $5^{a}$ & $6^{\mathrm{a}}$ & $7^{a}$ & $8^{\mathrm{a}}$ & $9^{a}$ & $10^{\mathrm{a}}$ \\
\hline KPI-1 & Process duration (min.) & 85 & 110 & 93 & 120 & 63 & 190 & 100 & 175 & 84 & 65 \\
\hline$K P I-1 a$ & (a) Product disposition & 85 & 110 & & & 63 & & & & & 65 \\
\hline$K P I-1 b$ & (b) Intervention & & & 93 & 120 & & & 100 & & 84 & \\
\hline KPI-1c & (c) recycling/cannibalization & & & & & & 190 & & 175 & & \\
\hline KPI-2 & Customer response time (min.) & 55 & 65 & 73 & 100 & 35 & 100 & 43 & 95 & 40 & 35 \\
\hline KPI-3 & $\begin{array}{l}\text { Autonomy and confidence of workers (1-5 } \\
\text { points) }\end{array}$ & 3.5 & 3.5 & 3.5 & 3.83 & 4.33 & 3.83 & 4.33 & 4 & 4.5 & 4.33 \\
\hline
\end{tabular}

\subsection{Results and Hypotheses' Verification}

An ANOVA statistical analysis for the hypotheses' verification was performed. Some statistical parameters (mean, standard deviation and $90 \%$ confidence levels limits) for the different KPI's under two scenarios (pre- and post-RLP formalization) are shown in Table 5.

Table 5. Some statistical parameters of the different KPI's under two scenarios: pre- and post-RLP formalization.

\begin{tabular}{|c|c|c|c|c|c|}
\hline \multirow[b]{2}{*}{ KPI } & \multirow[b]{2}{*}{ Factor } & \multicolumn{2}{|c|}{ Statistical Parameters } & \multicolumn{2}{|c|}{ 90\% Confidence Level } \\
\hline & & Mean & $\begin{array}{l}\text { Standard } \\
\text { Deviation }\end{array}$ & Lower Level & Upper Level \\
\hline \multirow{2}{*}{ Process duration (min.) } & pre-formalization & 199.20 & 104.64 & 134.34 & 264.06 \\
\hline & post-formalization & 108.50 & 42.98 & 81.86 & 135.14 \\
\hline \multirow{2}{*}{ Customer response (min.) } & pre-formalization & 110.30 & 64.20 & 70.51 & 150.09 \\
\hline & post-formalization & 64.10 & 26.70 & 47.55 & 80.65 \\
\hline \multirow{2}{*}{$\begin{array}{l}\text { Autonomy and Confidence of } \\
\text { workers ( } 1-5 \text { points })\end{array}$} & pre-formalization & 2.40 & 0.24 & 2.25 & 2.55 \\
\hline & post-formalization & 3.97 & 0.39 & 3.72 & 4.21 \\
\hline
\end{tabular}


The one-factor ANOVA statistical analysis was carried out for each dependent variable, in this case, the three KPI's. This one factor was regarded to the two different scenarios, that is, pre- and post-RLP formalization.

ANOVA analysis ( $90 \%$ confidence level) based on $\mathrm{F}$ ratio performed for each one of the KPI's indicated that there were statistically significant differences between the means obtained for the two levels of the pre- and post-RLP formalization factor.

More specifically with respect to the initially stated hypotheses (See H1-H3 in Section 5.1):

For this first hypothesis, $\mathrm{F}(1.18)=6.31, p=0.02$ and therefore there are statistically significant differences between the means of the two scenarios, that is, pre-and post-RLP formalization.

It can be stated that KPI-1 average duration of the RLP has been substantially reduced since the formalization of the process, which shows that H1 is fulfilled. More precisely, the difference between means test indicates with a $90 \%$ confidence level that the average duration of the RLP would be reduced between 27.20 and 154.20 minutes.

For this second hypothesis, $\mathrm{F}(1.18)=4.41, p=0.05$ and therefore there are statistically significant differences between the means of the two scenarios.

It can be stated that KPI-2 customer response time has also been reduced since the formalization of the RLP, which shows that $\mathrm{H} 2$ is also fulfilled. More precisely, the difference between means test indicates with a $90 \%$ confidence level that the customer response would be reduced between 7.19 and 85.21 minutes.

For the third hypothesis, $\mathrm{F}(1.18)=117.72, p=2.51 \times 10^{-9}$ and therefore there are statistically significant differences between the means of the two scenarios.

These values show that $\mathrm{H} 3$ is also fulfilled and that, therefore, the formalization of the RLP increases KPI-3 level of autonomy and confidence of the workers. More precisely, the difference between means test indicates with a 90\% confidence level that this KPI-3 would be increased between 1.32 and 1.82 points.

The results obtained allow us to definitively demonstrate the validity of the three working hypotheses initially proposed and, therefore, to affirm that: the formalization of the RLP reduces its duration, reduces the response time to the client and increases the level of autonomy and confidence of the workers participating in it. This, in turn, allows us to infer, as explained at the beginning of this section, that the tool proposed in this work, the RM-RLP, is useful for the formalization of the RLP insofar as it works correctly and provides the expected advantages. Similarly, given the important relationship between the RLP and the sustainability of the CS, it can be concluded that the formalization of the RLP helps to reduce process times, to make better decisions and to improve customer service, all of which has a positive impact on the sustainability of the CS.

\section{Conclusions}

The RLP has become a key competence of modern SCs, mainly for its importance in managing product disposal to recover their value and to enhance sustainability outcomes by helping firms to comply with government regulations on reducing the use of raw materials and waste generations, and to improve their image for customers and society in general.

One aspect that hinders firms achieving the full potential of the RLP and to benefit from all its advantages is not formalizing this process. Having a formalized RLP allows firms to eliminate ambiguity and to clarify priorities of activities, reduce complexity, improve worker satisfaction, properly manage customer expectations of returns and, in short, enhance their performance.

Despite formalizing the RLP being very important for SC efficiency and effectiveness, it is no easy task to identify, define, model or document its activities. The consulted works on this matter clearly identify the problem but, as far as we can see, they do not offer any specific tools or solutions for firms' practitioners to make progress in formalizing the RLP.

In order to bridge this gap, the present work proposes RM for the RLP so that firms can use it as a pattern or an example and to formalize their own RLP. The proposed RM 
includes and represents the three key stages of the process in detail: (1) collection and transport, when all the activities are performed from the time a customer contacts the company to the time when the product reaches its facilities; (2) inspection and evaluation, when each product is physically inspected and a decision is made about its disposition or the treatment that they, or their components, undergo; and (3) product disposition, when all the necessary activities are performed, from deciding which treatment to apply to each product (and its components), to placing it at the customer's disposal again or it being re-introduced into the manufacturing process or its elimination in a controlled manner.

During RM, special attention is paid to one of the critical decisions made in the RLP and the DD, and also to the different product treatment alternatives.

In order to supplement this RM, a 3-step methodology has been developed to help firms to swiftly and simply formalize and design their own models: step 1, specify the disposition alternatives applicable to the particular case; step 2, revise and adapt the reference process operations to the particular case; and step 3, model the RLP adapted to the particular case after bearing in mind the information collected in previous steps.

The applicability of the proposed RM-RLP covers all types of companies or SCs in charge of RLP management that aim to benefit from the advantages of its formalization. To prove its applicability, the proposed RM-RLP and methodology have been applied to an SC that manufactures relaxing chairs and is located in the province of Valencia (Spain), in an important furniture manufacturers cluster. This real application case demonstrated that formalizing the RLP can lead to improvements being made in three key indicators: total RLP duration, customer response time and the perceived autonomy and trust of the workers participating in the RLP. Apart from proving the usefulness of the proposal, this application to a real case can act as a guide for future applications.

The managerial implications of this study are: (a) the proposed RM-RLP aims to be an aid to industry managers to formalize their own RLP from a generic or reference RLP model, therefore gaining the formalization advantages such as reducing process times, increasing level of autonomy and confidence of the workers and improving customer service, all of them having a positive impact on the sustainability of the SC; (b) the proposed methodology guides managers and users on the way of adapting this RM-RLP (the application to a real company has served as an application example); (c) the RM-RLP gives the managers a holistic and detailed vision of the RLP that it is often difficult to obtain because the RLP usually is a distributed process executed by several participants along the SC; (d) the RM-RLP leads the managers to identify the main and most important decisions in the RLP, not only the DD, but others related with economic customer compensation or with the transport management; (e) the necessary training in BPMN language and the development of a new RLP model has increased the knowledge and skills of the workers and make it possible for the subsequent modelling of other processes in the company, which is very appreciated by the top management to update the graphical documents and quality manuals in the quality management system; and (f) the willingness of workers to collaborate, especially to develop the new RLP model and to collect the data for the KPIs evaluation has been critical for the proposal application and for the success of the study.

Summarizing, through this study the following main findings have been obtained: (a) While there is much literature related to RLP formalization and its advantages, and many works show the main RLP macro-activities, no research has been conducted to offer a graphical overview of the generic RLP in sufficient detail that can serve as a reference for companies to formalize their own RLP; (b) in this work, a RM-RLP complemented with a methodology and an application example to guide companies to formalize their RLP is presented, and (c) the application results show that the RM-RLP and methodology proposed are useful to formalize the RLP and allow the benefits related to the process formalization to be reached, such as reduce process times, make better decisions and improve customer service, all of them having a positive impact on the sustainability of the SC. 
Nevertheless, it is important to remark that this work is subjected to some limitations. One of the limitations of the RM-RLP herein proposed is that its usefulness decreases when it is used for the formalization of very specific RLPs or with significant differences in respect to standard processes. For these cases, the differences between the proposed reference model and the formalized process can be numerous and, obviously, the RM usefulness will decrease. Another limitation of the RM-RLP is that it does not cover the RLP improvement phase. The proposed model aims to help to formalize the RLP in its current state. It is true to state that when firms attempt to formalize their RLP by comparing it to RM, they can identify possibilities to improve their current process. However, the aim of our proposal is not to improve this process but to formalize it. Therefore, a future research line would be to study the possibility of extending the proposed methodology, which currently aims to only formalize the RLP, so that it can also help to improve the RLP while it is being formalized. To this end, we believe that it is essential to start by reviewing existing methodologies to improve business processes.

Another future research line has to do with including systems that measure performance for the RLP. Based on our experience, recently formalized processes tend to operate quite well for the first days or weeks, but workers tend to move away from the formalized process with time. Thus, we believe that it would be interesting to set up a control system to ensure that the RLP is run in such a way that its successive iterations barely move away from the procedure or formalized model. We also consider it interesting for the control system set up in the RLP to allow the specific impact that formalization has on a firm's sustainability levels to be assessed.

Finally, applying the RM-RLP to other SCs in other sectors will allow a repository of application cases to be obtained which could be used to collect good practices and to favor the application of new cases, while also producing valuable feedback to continuously improve the proposal.

Author Contributions: Design and conceptualization F.A. and P.C.-P.; introduction, F.A. and P.C.-P.; background, F.A., D.P.-P. and A.M.-R.; reference model and methodology proposal, F.A., P.C.-P. and D.P.-P.; obtaining data, P.C.-P.; application example, P.C.-P. and F.A.; validation of the proposal, F.A., P.C.-P. and A.M.-R.; conclusions, F.A., A.M.-R. and D.P.-P.; writing original draft, F.A. and P.C.-P.; writing review and finishing, P.C.-P., D.P.-P. and A.M.-R. All authors have read and agreed to the published version of the manuscript.

Funding: This research received no external funding.

Institutional Review Board Statement: Not applicable.

Informed Consent Statement: Not applicable.

Data Availability Statement: Not applicable.

Acknowledgments: The authors would like to acknowledge the predisposition of the furniture company by facilitating all necessary data to be used in the example application.

Conflicts of Interest: The authors declare no conflict of interest.

\section{References}

1. Hanafi, J.; Kara, S.; Kaebernick, H. Reverse logistics strategies for end-of-life products. Int. J. Logist. Manag. 2008, 19, 367-388. [CrossRef]

2. Han, X.; Wu, H.; Yang, Q.; Shang, J. Reverse channel selection under remanufacturing risks: Balancing profitability and robustness. Int. J. Prod. Econ. 2016, 182, 63-72. [CrossRef]

3. Prakash, C.; Barua, M.K. A combined MCDM approach for evaluation and selection of third-party reverse logistics partner for Indian electronics industry. Sustain. Prod. Consum. 2016, 7, 66-78. [CrossRef]

4. Ravi, V.; Shankar, R.; Tiwari, M. Analyzing alternatives in reverse logistics for end-of-life computers: ANP and balanced scorecard approac. Comput. Ind. Eng. 2005, 48, 327-356. [CrossRef]

5. García-Arca, J.; Garrido, A.T.G.-P.; Prado-Prado, J.C. 'Sustainable packaging logistics'. The link between sustainability and competitiveness in supply chains. Sustainability 2017, 9, 1098. [CrossRef] 
6. Steeneck, D.W.; Sarin, S.C. Pricing and production planning for reverse supply chain: A review. Int. J. Prod. Res. 2013, 51, 6972-6989. [CrossRef]

7. Pokharel, S.; Mutha, A. Perspectives in reverse logistics: A review. Resour. Conserv. Recycl. 2009, 53, 175-182. [CrossRef]

8. Barker, T.; Zabinsky, Z.B. Designing for recovery-A solid reverse supply chain can help you recover, renew, recycle. Ind. Eng. 2010, 42, 38.

9. Shankar, R.; Ravi, V.; Tiwari, M.K. Analysis of interaction among variables of reverse logistics: A system dynamics approac. Int. J. Logist. Syst. Manag. 2008, 4, 1-20. [CrossRef]

10. Carter, C.; Ellram, L. Reverse logistics-A review of the literature and framework for future investigation. J. Bus. Logist. 1998, 19, 85-102.

11. Rogers, D.S.; Tibben-Lembke, R.S. Going Backwards: Reverse Logistics Trends and Practice; Reverse Logistics Executive Council: Reno, NV, USA, 1998; pp. 37-72.

12. Banihashemi, T.A.; Fei, J.; Chen, P.S.-L. Exploring the relationship between reverse logistics and sustainability performance. Mod. Supply Chain Res. Appl. 2019, 1, 2-27. [CrossRef]

13. Presley, A.; Meade, L.; Sarkis, J. A strategic sustainability justification methodology for organizational decisions: A reverse logistics illustration. Int. J. Prod. Res. 2007, 45, 4595-4620. [CrossRef]

14. Agrawal, S.; Singh, R.K.; Murtaza, Q. Triple bottom line performance evaluation of reverse logistics. Compet. Rev. 2016, 26, 289-310. [CrossRef]

15. Taleizadeh, A.A.; Haghighi, F.; Niaki, S.T.A. Modeling and solving a sustainable closed loop supply chain problem with pricing decisions and discounts on returned products. J. Clean. Prod. 2019, 207, 163-181. [CrossRef]

16. Autry, C.W. Formalization of reverse logistics programs: A strategy for managing liberalized returns. Ind. Mark. Manag. 2005, 34, 749-757. [CrossRef]

17. Meade, L.M.; Sarkis, J.; Presley, A. The theory and practice to Reverse Logistics. Int. J. Logist. Syst. Manag. 2007, 3, 56-84. [CrossRef]

18. Shaharudin, M.R.; Govindan, K.; Zailani, S.; Tan, K.C.; Iranmanesh, M. Product return management: Linking product returns, closed-loop supply chain activities and the effectiveness of the reverse supply chains. J. Clean. Prod. 2017, 149, 1144-1156. [CrossRef]

19. Rogers, D.S.; Tibben-Lembke, R. An examination of reverse logistics practices. J. Bus. Logist. 2001, 22, 129-148. [CrossRef]

20. Dey, A.; LaGuardia, P.; Srinivasan, M. Building sustainability in logistics operations: A research agenda. Manag. Res. Rev. 2011, 34, 1237-1259. [CrossRef]

21. Tibben-Lembke, R.S.; Rogers, D.S. Differences between forward and reverse logistics in a retail environment. Supply Chain Manag. An Int. J. 2002, 7, 271-282. [CrossRef]

22. Turrisi, M.; Bruccoleri, M.; Cannella, S. Impact of reverse logistics on supply chain performance. Int. J. Phys. Distrib. Logist. Manag. 2013, 43, 564-585. [CrossRef]

23. Guide, V.D.R., Jr.; Van Wassenhove, L.N. The reverse supply chain. Harv. Bus. Rev. 2002, 80, 25-26.

24. Huscroft, J.; Hazen, B.; Hall, D.J.; Skipper, J.B.; Hanna, J.B. Reverse logistics: Past research, current management issues, and future directions. Int. J. Logist. Manag. 2013, 24, 304-327. [CrossRef]

25. Pugh, D.S.; Hickson, D.J.; Hinings, C.R.; Turner, C. Dimensions of Organization Structure. Adm. Sci. Q. 1968, 13, 65. [CrossRef]

26. Richey, R.G.; Chen, H.; Genchev, S.E.; Daugherty, P.J. Developing effective reverse logistics programs. Ind. Mark. Manag. 2005, 34, 830-840. [CrossRef]

27. Hartline, M.D.; Maxham, J.G.; McKee, D.O. Corridors of influence in the dissemination of customer-oriented strategy to customer contact service employees. J. Mark. 2000, 64, 35-50. [CrossRef]

28. Genchev, S.E.; Richey, R.G.; Gabler, C.B. Evaluating reverse logistics programs: A suggested process formalization. Int. J. Logist. Manag. 2011, 22, 242-263. [CrossRef]

29. Aitken, J.; Harrison, A. Supply governance structures for reverse logistics systems. Int. J. Oper. Prod. Manag. 2013, 33, 745-764. [CrossRef]

30. Walker, O.C.; Ruekert, R.W. Marketing's Role in the Implementation of Business Strategies: A Critical Review and Conceptual Framework. J. Mark. 1987, 51, 15. [CrossRef]

31. Ruekert, R.W.; Walker, O.C.; Roering, K.J. The Organization of Marketing Activities: A Contingency Theory of Structure and Performance. J. Mark. 1985, 49, 13. [CrossRef]

32. Genchev, S.E. Reverse logistics program design: A company study. Bus. Horiz. 2009, 52, 139-148. [CrossRef]

33. Hui, H. Managing Reverse Logistics in Social Commerce Platforms: Theory, Methods and Applications. Ph.D. Thesis, Technical University of Madrid, Madrid, Spain, July 2017.

34. Richey, R.G.; Genchev, S.E.; Daugherty, P.J. The role of resource commitment and innovation in reverse logistics performance. Int J. Phys. Distrib. Logist. Manag. 2005, 35, 233-257. [CrossRef]

35. Hazen, B.T.; Hall, D.J.; Hanna, J.B. Reverse logistics disposition decision-making: Developing a decision framework via content analysis. Int. J. Phys. Distrib. Logist. Manag. 2012, 42, 244-274. [CrossRef]

36. Malone, R. Closing the Supply Chain Loop: Reverse Logistics and the SCOR Model. Inbound Logist. 2004, 24, 217-222.

37. Huscroft, J.R. The Reverse Logistics Process in the Supply Chain and Managing Its Implementation. Ph.D. Thesis, Auburn University, Auburn, Alabama, December 2010. 
38. Ansari, Z.N.; Kant, R. A state-of-art literature review reflecting 15 years of focus on sustainable supply chain management. J. Clean. Prod. 2017, 142, 2524-2543. [CrossRef]

39. Koberg, E.; Longoni, A. A systematic review of sustainable supply chain management in global supply chains. J. Clean. Prod. 2019, 207, 1084-1098. [CrossRef]

40. Carter, C.R.; Rogers, D.S. A framework of sustainable supply chain management: Moving toward new theory. Int. J. Phys. Distrib. Logist. Manag. 2008, 38, 360-387. [CrossRef]

41. Ahi, P.; Searcy, C. A comparative literature analysis of definitions for green and sustainable supply chain management. J. Clean. Prod. 2013, 52, 329-341. [CrossRef]

42. Seuring, S.; Sarkis, J.; Müller, M.; Rao, P. Sustainability and supply chain management-An introduction to the special issue. J. Clean. Prod. 2008, 16, 1545-1551. [CrossRef]

43. Ji, G.; Gunasekaran, A.; Yang, G. Constructing sustainable supply chain under double environmental medium regulation. Int. J. Prod. Econ. 2014, 147, 211-219. [CrossRef]

44. Bastas, A.; Liyanage, K. Integrated quality and supply chain management business diagnostics for organizational sustainability improvement. Sustain. Prod. Consum. 2019, 17, 11-30. [CrossRef]

45. Sarkis, J.; Helms, M.M.; Hervan, A.A. Reverse logistics and social sustainability. Corp. Soc. Responsib. Environ. Manag. 2010, 17, 337-354. [CrossRef]

46. Guarnieri, P.; Silva, L.C.; de Oliveira Vieira, B. How to Assess Reverse Logistics of E-Waste Considering a Multicriteria Perspective? A Model Proposition. Logistics 2020, 4, 25. [CrossRef]

47. Geng, R.; Mansouri, S.A.; Aktas, E. The relationship between green supply chain management and performance: A meta-analysis of empirical evidences in Asian emerging economies. Int. J. Prod. Econ. 2017, 183, 245-258. [CrossRef]

48. Narayana, S.A.; Elias, A.A.; Pati, R.K. Reverse logistics in the pharmaceuticals industry: A systemic analysis. Int. J. Logist. Manag. 2014, 25, 379-398. [CrossRef]

49. Winter, M.; Knemeyer, A.M. Exploring the integration of sustainability and supply chain management: Current state and opportunities for future inquiry. Int. J. Phys. Distrib. Logist. Manag. 2013, 43, 18-38. [CrossRef]

50. Morgan, T.R.; Tokman, M.; Richey, R.G.; Defee, C. Resource commitment and sustainability: A reverse logistics performance process model. Int. J. Phys. Distrib. Logist. Manag. 2018, 48, 164-182. [CrossRef]

51. Alarcón, F.; Cortés-Pellicer, P.; Pérez-Perales, D.; Sanchis, R. Sustainability vs. Circular economy from a disposition decision perspective: A proposal of a methodology and an applied example in SMEs. Sustainability 2020, 12, 10109. [CrossRef]

52. Lindsay, A.; Downs, D.; Lunn, K. Business processes-Attempts to find a definition. Inf. Softw. Technol. 2003, 45, 1015-1019. [CrossRef]

53. Hammer, M.; Champy, J. Reengineering the corporation: A manifesto for business revolution. Bus. Horiz. 1993, 36, 90-91. [CrossRef]

54. Fleischmann, M.; Krikke, H.R.; Dekker, R.; Flapper, S.D.P. A characterisation of logistics networks for product recovery. Omega 2000, 28, 653-666. [CrossRef]

55. de Brito, M.P.; Dekker, R. A Framework for Reverse Logistics. In Reverse Logistics; Springer: Berlin/Heidelberg, Germany, 2004; pp. 3-27.

56. Agrawal, S.; Singh, R.K.; Murtaza, Q. A literature review and perspectives in reverse logistics. Resour. Conserv. Recycl. 2015, 97, 76-92. [CrossRef]

57. Sangwan, K.S. Key Activities, Decision Variables and Performance Indicators of Reverse Logistics. Procedia CIRP 2017, 61, 257-262. [CrossRef]

58. Sellitto, M.A. Reverse logistics activities in three companies of the process industry. J. Clean. Prod. 2018, 187, 923-931. [CrossRef]

59. Tüzün Rad, S.; Gülmez, S. Green logistics for sustainability. Int. J. Manag. Econ. Bus. 2017, 13, $603-614$.

60. Han, H.; Ponce-Cueto, E. Formalization of reverse logistics programs: A theoretical framewor. Artic. Braz. J. Oper. Prod. Manag. 2016, 13, 160-172. [CrossRef]

61. Silver, B. BPMInstitute.org / Business Process Management (BPM) Training and Education. 2009. Available online: https: / / www.bpminstitute.org/ (accessed on 30 July 2021).

62. Cottrill, K. Return to sender. Traffic World 2000, 262, 17-34.

63. Merritt, K. Integrated reverse logistics solution allows Levi Strauss. Front. Solut. 2001, 2, 41.

64. Stock, J.R. Development and Implementation of Reverse Logistics Programs. Counc. Logist. Manag. 1998, $39,54-55$.

65. Baum, J.R.; Wally, S. Strategic decision speed and firm performance. Strateg. Manag. J. 2003, 24, 1107-1123. [CrossRef]

66. Dahlstrom, R.; McNeilly, K.M.; Speh, T.W. Buyer-seller relationships in the procurement of logistical services. J. Acad. Mark. Sci. 1996, 24, 110-124. [CrossRef]

67. Bowersox, D.J.; Daugherty, P.J. Logistics Leadership_Logistics Organizations of the Future. Logist. Inf. Manag. 1992, 5, 12-17. [CrossRef]

68. Hall, D.J.; Huscroft, J.R.; Hazen, B.T.; Hanna, J.B. Reverse logistics goals, metrics, and challenges: Perspectives from industry. Int. J. Phys. Distrib. Logist. Manag. 2013, 43, 768-785. [CrossRef]

69. Genchev, S.E. Assessing reverse logistics complexity: Conceptual model, scale development, and a case study. Diss. Abstr. Int. Sect. A Humanit. Soc. Sci. 2007, 69, 297.

70. Barney, J.B. Gaining and Sustaining Competitive Advantage. Pearson High. 1997, 17, 99-120. 
71. Fredrickson, J.W. The Strategic Decision Process and Organizational Structure. Acad. Manag. Rev. 1986, 11, 280-297. [CrossRef]

72. Autry, C.W.; Daugherty, P.J.; Glenn Richey, R. The challenge of reverse logistics in catalog retailing. Int. J. Phys. Distrib. Logist. Manag. 2001, 31, 26-37. [CrossRef]

73. Daugherty, P.J. Review of logistics and supply chain relationship literature and suggested research agenda. Int. J. Phys. Distrib. Logist. Manag. 2011, 41, 16-31. [CrossRef]

74. Lacerda, L. Logística Reversa: Uma visão sobre os conceitos básicos e as práticas operacionais. Cent. Estud. em Logística 2002, 9 , $18-35$.

75. Eisenhardt, K.M. Control: Organizational and economic approaches. Manag. Sci. 1985, 31, 134-149. [CrossRef]

76. La Rosa, M.; Lux, J.; Seidel, S.; Dumas, M.; Ter Hofstede, A.H.M. Questionnaire-driven configuration of reference process models. In Lecture Notes in Computer Science (Including Subseries Lecture Notes in Artificial Intelligence and Lecture Notes in Bioinformatics); Springer: Berlin/Heidelberg, Germany, 2007; Volume 4495, pp. 424-438.

77. Agrawal, S.; Singh, R.K. Analyzing disposition decisions for sustainable reverse logistics: Triple Bottom Line approach. Resour. Conserv. Recycl. 2019, 150, 104-148. [CrossRef]

78. Skinner, L.R.; Bryant, P.T.; Glenn Richey, R. Examining the impact of reverse logistics disposition strategies. Int. J. Phys. Distrib. Logist. Manag. 2008, 38, 518-539. [CrossRef]

79. Mangla, S.K.; Kusi-Sarpong, S.; Luthra, S.; Bai, C.; Jakhar, S.K.; Kha, S.A. Operational excellence for improving sustainable supply chain performance. Resour. Conserv. Recycl. 2020, 162, 105025. [CrossRef]

80. EFIC-European Furniture Industries Confederation. Available online: https://www.efic.eu/ (accessed on 1 August 2021).

81. Forrest, A.; Hilton, M.; Ballinger, A.; Whittaker, D. Circular Economy Opportunities in the Furniture Sector. Eur. Environ. Bur. 2017, 55, 1-45. 